This manuscript is for the proposed special volume of:

"Characterization of hydrate-bearing sediments from the 2012-13 Methane Hydrate Resources in Japan drilling program in the Eastern Nankai Trough (Gas hydrate drilling in Eastern Nankai)"

- Title

\title{
Hydro-Bio-Geomechanical Properties of Hydrate-Bearing Sediments from Nankai Trough
}

\section{- Authors and affiliations}

Santamarina, J.C. ${ }^{\mathrm{a}}$, Dai, S., ${ }^{\mathrm{a}, 1}$, Terzariol, M. ${ }^{\mathrm{a}}$, Jang, J. ${ }^{\mathrm{a}}$, Waite, W.F. ${ }^{\mathrm{b}}$, Winters, W.J. ${ }^{\mathrm{b}}$, Nagao, J. ${ }^{\mathrm{c}}$, Yoneda, J. ${ }^{\mathrm{c}}$, Konno, Y. ${ }^{\mathrm{c}}$, Fujii, T. ${ }^{\mathrm{d}}$, Suzuki, K. ${ }^{\mathrm{d}}$

${ }^{\text {a }}$ Georgia Institute of Technology, Atlanta, GA, United States

${ }^{\mathrm{b}}$ U.S. Geological Survey, Woods Hole, MA, United States

${ }^{c}$ National Institute of Advanced Industrial Science and Technology, Sapporo, Japan

${ }^{\mathrm{d}}$ Japan Oil, Gas and Metals National Corporation, Tokyo, Japan

\section{- Corresponding Author}

William F. Waite

Phone: (508) 457-2346

U.S. Geological Survey

Email: wwaite@usgs.gov

384 Woods Hole Road

Woods Hole, MA 02543

United States of America

- Present affiliation

${ }^{1}$ S. Dai now at: National Energy Technology Laboratory, Morgantown, WV, United States

- Keywords

Methane hydrate; Hydrate-bearing sediment; Nankai Trough; Physical properties; Pressure core 
study, sediment microbial communities were successfully extracted and stored under highpressure, anoxic conditions. Depressurized samples of these extractions were incubated in air, where microbes exhibited temperature-dependent growth rates.

\section{Introduction}

A hydraulic, geomechanical, and biological characterization of hydrate-bearing sediments from the Nankai Trough, offshore Japan, was conducted during the first deployment of a suite of Pressure Core Characterization Tools (PCCTs) as part of a collaborative pressure-core study led by the Research Consortium for Methane Hydrate Resources in Japan (MH21) and funded by the Ministry of Economy, Trade and Industry (METI) (Yamamoto et al., 2012; Yamamoto, 2015). PCCTs are designed to maintain the high pressure needed to keep hydrate stable during the entire process of transferring, subsampling, and testing hydrate-bearing sediments in cores collected and retained at near-in situ pressures (Santamarina et al., 2012a; 2012b). PCCT measurements provide a comprehensive set of parameters needed for borehole-stability analyses, reservoirproduction simulations, and in situ characterization of the hydrate-bearing system.

The Nankai Trough is located southeast of Japan, from offshore Tokai to offshore Kyushu, and has extensively developed forearc basins and accretionary prisms. Thrust and growth faults, as well as bottom-simulating reflectors (BSRs) suggestive of the presence of hydrate, have been extensively investigated since 1971 with seismic surveys, coring, and logging (Matsumoto et al., 2004; Takahashi and Tsuji, 2005; Tsuji et al., 2004; Uchida et al., 2004; Waseda and Uchida, 2004a, b). The total amount of gas in place in the eastern Nankai Trough is estimated to be 1.1 trillion $\left(10^{12}\right)$ cubic meters (Fujii et al., 2008). Isotope analyses suggest the methane gas in shallow sections of the Nankai Trough at the coring site for this study is mostly 
microbial, with only a slight increase of higher hydrocarbon concentrations with depth (Kida et al., 2015). A minor contribution of thermogenic methane near mud volcanoes at the Kumanonada area has also been observed (Uchida et al., 2009).

This pressure-core characterization study reported herein is a joint effort of the Georgia Institute of Technology (Georgia Tech), U.S. Geological Survey (USGS), Japan Oil Gas and Metals National Corporation (JOGMEC), and the National Institute of Advanced Industrial Science and Technology (AIST). The study utilizes pressure cores recovered from hydratebearing sediments in hole AT1-C, on the north slope of Daini Atsumi Knoll off the Atsumi and Shima peninsulas. A location overview is provided by Yamamoto (2015), and a more precise location map is given by Fujii et al. (2015). Pressure cores were collected during the third hydrate drilling program at Nankai Trough from June 29th to July 4th of 2012 (Yamamoto et al., 2012). Water depth at this drilling location is $\sim 1000 \mathrm{~m}$ and hydrate deposits are approximately $300 \mathrm{~m}$ below the seafloor within the deep submarine-fan turbidite system. The 60-m coring interval, from $\sim 1270 \mathrm{~m}$ to $\sim 1330 \mathrm{~m}$ below sea level, includes a clayey-silt overburden zone and a methane hydrate concentration zone (MHCZ) containing clayey-silt, sandy-silt and silty-sand layers (Ito et al., 2015). Most gas hydrates at this site occur in the pore spaces of unconsolidated silty-sand sediments. The first methane production test from marine gas hydrates was accomplished at this AT1 site in early 2013 (Fujii et al., 2013; Yamamoto, 2013).

\section{Core Handling}

The 2012 Nankai Trough pressure-coring program provided an opportunity to examine minimally-disturbed, hydrate-bearing sediment acquired and continuously held at high pressure and within the hydrate-stability conditions. Pressure cores were cut and stored at sea in $1.2 \mathrm{~m}-$ 
long pressurized storage vessels held at 20MPa in a refrigerated van (Inada et al., 2015). Post cruise, the storage vessels were transferred to the AIST facility in Sapporo, where they were monitored and held at a pressure of $\sim 20 \mathrm{MPa}$ and a temperature of $\sim 5^{\circ} \mathrm{C}$. For PCCT analysis, cores were transported to cold rooms held at $\sim 4-6^{\circ} \mathrm{C}$. Suzuki et al. (2015) show the pressure and temperature history of one pressure core throughout the collection, transport and storage process.

To reduce stress on PCCT pressure seals and pumps, the operating pressure was chosen to be $10 \mathrm{MPa}$ rather than the $20 \mathrm{MPa}$ at which the cores were stored. Because methane hydrate is stable above $4.7 \mathrm{MPa}$ at $6^{\circ} \mathrm{C}$ (Sloan and Koh, 2007), depressurizing from 20 to $10 \mathrm{MPa}$ prior to PCCT testing does not induce any of the sample degradation associated with departures from the methane hydrate stability conditions (Waite et al., 2008). The solubility of methane in the pore water is also a consideration because in the absence of methane hydrate, methane solubility drops during depressurization, and methane coming out of solution as gas can severely affect the mechanical properties of unconsolidated sediment during depressurization (Yun et al., 2006). In the presence of stable hydrate however, methane does not come out of solution to form gas bubbles during depressurization because the methane solubility actually increases slightly as pressure decreases (Lu et al., 2008). Based on the analysis of Dai and Santamarina (2014), the solubility increase is expected to result in a negligible $0.1 \%$ hydrate saturation decrease for the Nankai Trough cores analyzed in this study.

The three pressure cores described in this study are: AT1-C-8P(133-227), AT1-C10P(33-152.5), and AT1-C-20P(72-145), denoted here as 8P, 10P and 20P, respectively. All pressure cores in this study had a diameter of $50.8 \mathrm{~mm}$ and a maximum length of $1.2 \mathrm{~m}$.

\section{Devices, Procedure, and Data Reduction}


Pressure core characterization tools PCCTs are shown schematically in Fig. 1 (Santamarina et al., 2012a; 2012b). These tools were deployed in the AIST facility in Sapporo, Japan to transfer, subsample, and characterize the AT1-C Nankai Trough pressure cores while maintaining near in situ pressure and temperature conditions. Throughout the PCCT testing program, unless specifically noted, the pressurizing fluid is an artificial brine made by mixing $\sim 30$ parts per thousand iodine-free salt with pure water. Cores were extracted from their storage chambers at pressure and held using the PCCT manipulator (Fig. 1A). Cores 8P and 10P were tested in the Instrumented Pressure Testing Chamber IPTC prior to being subsectioned under pressure using the PCCT saw for study in other PCCT devices. Cut and measurement locations are shown in Fig. 2. Test procedures used in the individual PCCTs are given below.

\subsection{Instrumented Pressure Testing Chamber, IPTC}

The IPTC measures P- and S-wave velocities, undrained shear strength, and electrical conductivity at preselected locations along a core (Yun et al., 2006). Four opposing sensor port pairs are spaced along the length of the IPTC (Fig. 1A). The first sensor pair contains drills for penetrating the core liner. As the core is advanced through the ITPC, sensors are inserted through the holes in the liner and brought directly into contact with the core sediment. Measurements are made at a given hydrostatic stress, but with no applied effective stress. P-wave velocity measurements $V_{P}$ are made using $1 \mathrm{MHz}$ P-wave pinducers. S-wave velocity measurements $V_{S}$ are made using $\mathrm{S}$-wave bender elements, each encased in silicone to make a circular pad with which to contact the specimen and transmit/receive a shear wave. The final port pair contains a $5.6 \mathrm{~mm}$-diameter cone penetrometer in the top port for measuring undrained shear strength $S_{u}$ and a $2.1 \mathrm{~mm}$-diameter, single-wedge, $20 \mathrm{kHz}$ electrical conductivity $\sigma_{e l}$ needle probe in the bottom port. 


\subsection{Effective Stress Chamber, ESC}

The ESC chamber, shown schematically in Fig. 1B, not only maintains hydrate pressuretemperature P-T stability conditions, but is also capable of directly accepting a core at pressure and restoring stress-controlled boundary conditions: the lateral stress $\sigma_{h}{ }^{\prime}$ is controlled using the pressurizing brine against a soft membrane jacket. The effective vertical stress $\sigma_{v}{ }^{\prime}$ is controlled using a loading piston reacted against an external load frame. The in situ $\sigma_{v}{ }^{\prime}$ is calculated from the sub-sea floor depth of each core and the average unit weight of the overlying sediment, 8.16 $\mathrm{kN} / \mathrm{m}^{3}$ (Fig. 2 shows overburden data for each core). For this study, the ESC is equipped to measure stress-volume responses and provides water permeability values for pressure-core specimens tested under in situ $P-T-\sigma_{v}{ }^{\prime}$ conditions.

A typical test sequence using the ESC consists of four stages: 1) accept and restore a specimen to the in situ effective stress using a standard oedometer test protocol; 2) characterize the hydrate-bearing specimen at in situ $P-T-\sigma^{\prime}$ conditions; 3) monitor the specimen behavior during hydrate dissociation and gas production; and 4) characterize the specimen postproduction. The pore fluid pressure, temperature, boundary stresses, and vertical deformation are continuously monitored during all stages.

To accept a pressure-core specimen, the ESC is set horizontally, aligned and coupled to the manipulator core transfer system, referred to as the MAN, and the PCCT saw, as described by (Santamarina et al., 2012a; 2012b). Once the specimen and core liner are cut to length, they are pushed into the ESC liner trap. The MAN control arm is retracted to the storage chamber so the ball valves on the ESC and MAN can be closed. Once the bridge between the ESC and MAN is depressurized, the ESC is decoupled and placed vertically within an external frame. A loading piston is then attached to the ESC and used to push the specimen out of the rigid core liner into 
the rubber jacket (Fig. 1B). Because the ESC does not contain an internal load cell, and the chamber pressure $u_{\text {cell }}$ is not measured in the specimen pore space, stresses on the specimen are expressed in terms of applied stress $F / A-u_{\text {cell }}$ rather than as effective vertical stress $\sigma_{v}{ }^{\prime}$. Values of $F / A-u_{\text {cell }}$ are directly measured and do not necessarily equal the actual effective vertical stress $\sigma_{v}$ ' experienced by the core specimen if transient pore pressures $u_{\text {pore }}$ exist inside the core. Note that force equilibrium gives: $F / A-u_{\text {cell }}=u_{\text {pore }}+\sigma_{v}{ }_{v}$, where $F$ is the implied force through the loading piston, $A$ is the specimen cross section, and $u_{\text {cell }}$ is the chamber pressure. The Direct Shear Chamber (introduced in section 3.3) adopts the same stress definition.

Water permeability is measured directly in both stage 2 (before hydrate dissociation) and stage 4 (after hydrate dissociation) at the in situ stress state, though with the confining fluid raised to $40-50 \mathrm{kPa}$ above the pore pressure to ensure there is no preferential fluid flow along the specimen boundary. According to Darcy's law, the intrinsic permeability of a porous medium $k$ can be computed as:

$$
k=\frac{q}{\nabla P / \mu},
$$

where $q$ is the fluid flux, $\nabla P$ is the pressure gradient given by the measured differential pressure $\Delta u$ over the specimen length $L$, and $\mu$ is the fluid viscosity. The water permeability of the hydrate-bearing sediment was obtained by pumping water at a constant flux $q$ while measuring the pressure difference $\Delta u$ across the specimen. The constant flow rate was controlled by a Teledyne ISCO 500D pump, and the differential pressure was measured using a high accuracy $(\sim 1 \mathrm{kPa}$ for in-line pressures of $10 \mathrm{MPa})$ Validyne, DP303 differential pressure transducer. Porous stones were placed on the loading pad and pedestal to spread the injected flow uniformly across the specimen's cross section. 
The hydraulic gradient used to measure water permeability is carefully selected. A small gradient requires a long test duration, and the measured pressure difference may fall below noise levels; on the other hand, large gradients impose pronounced effective stress gradients that unevenly compact the specimen and may cause fines migration. To avoid specimen compaction, the imposed fluxes were low, only large enough to generate differential pressures exceeding the transducer's $\sim 1 \mathrm{kPa}$ resolution limit at 10MPa. All tests in this study involved hydraulic gradients between 1 and 10.

\subsection{Direct Shear Chamber, DSC}

Cylindrical specimens tested under triaxial conditions will be affected by seating effects; this situation is aggravated by sub-sampling and transfer under high-pressure, as no remedial boundary trimming/correction can be implemented. Consequently, a double plane shear device was designed to determine shear strength by causing shear away from subsampling cutting surfaces. The shear box consists of a sliding stainless steel ring connected to an internal horizontal loading piston that generates a maximum shear displacement of $15 \mathrm{~mm}$. At all times, P-waves, temperature, water pressure, forces and displacements can be monitored.

The DSC is the first chamber to accurately measure shear strength of never-depressurized methane hydrate-bearing pressure cores under in situ hydrostatic pressure and vertical effective stress. This chamber includes (Fig. 1C): 1) the vertical loading piston, which like its counterpart in the ESC, is used to extrude the specimen from its rigid core liner and restore the in situ vertical effective stress. Piezo-crystals and thermocouples located in the base of the loading piston and in the pedestal are used to measure P-wave velocity and temperature respectively; 2) the transfer coupler with a flange for connecting with the PCCT manipulator; 3) liner trap and 4) shear box. 
Specimens are loaded into the shear box using the same steps described for the ESC in Section 3.2. An ISCO pump is connected to the chamber in order to maintain water pressure at $10 \mathrm{MPa}$, with an accuracy of $\pm 0.2 \mathrm{MPa}$. The effective vertical stress $\sigma_{v}{ }^{\prime}$ is calculated following the same analysis used for the ESC.

The test sequence starts by restoring the in situ vertical effective stress $\sigma_{v}$ ' using the loading piston. P-wave velocities are measured during this consolidation process. Once consolidation is complete, the specimen is held at its near in situ $\sigma_{v}$, and the specimen is sheared. Because the loading piston provides constant displacement rather than constant stress, stresses can change during shear. To perform the shear test at the given initial stress state, the shearing is accomplished through a series of $1 \mathrm{~mm}$ horizontal displacements and left to relax after each shear displacement. Once the shear loading is finished, the vertical loading piston is retracted to bring the sediment to zero vertical stress, the internal horizontal displacement ring is restored to its initial position and the specimen, still containing hydrate, is reloaded to $\sigma_{v}{ }^{\prime}=3 \mathrm{MPa}$. This is the initial condition for hydrate dissociation.

After hydrate dissociation, the specimen is subjected to a set of tests performed to characterize the hydrate-free sediment. The sequence reported here consists of the following steps: (1) specimen overburden is verified to be $\sigma_{v}{ }^{\prime}=3 \mathrm{MPa}$; (2) shear test; (3) vertical unloading and realignment of the shear ring; (4) reloading to $\sigma_{v}{ }^{\prime}=7.5 \mathrm{MPa} ;(5)$ shear test. Deformations and P-wave propagation velocities are determined throughout the complete test sequence.

\subsection{Bio-Chamber, BIO}

The BIO chamber deployment is intended as a proof-of-concept that sediment subsections can be collected and stored at pressure under anoxic conditions for subsequent biological studies. BIO consists of a sub-sampling chamber designed to collect multiple soil 
specimens and exchangeable high-pressure bio-reactors into which specimens can be transferred at pressure (Fig. 1D). The BIO system is loaded with a pressure-core subsection using the same steps described for the ESC chamber (Section 3.2). Once the BIO chamber is loaded with a pressure core, it is decoupled from the manipulator system and remains oriented with the core lying horizontally for the remainder of the test. A self-drilling thermocouple and a pressure transducer on the chamber record the chamber's temperature and pressure throughout the test sequence, and locking pins hold the specimen in position during the BIO subsampling process (Santamarina et al., 2012a).

The set sequence involves four main stages: in stage one, the chamber is held at pressure and temperature conditions within the stability field while the chamber-pressurizing water surrounding the specimen is replaced with argon gas. Gas is introduced into the system until gas begins flowing through the fluid drain at the lowest point in the BIO chamber. This replacement is conducted under almost constant pressure inside the stability field; the argon gas environment preserves anaerobic conditions and prevents contamination during bio-subsampling for biologic studies.

In stage two, a front scraper rod is used to remove the first $\sim 10 \mathrm{~mm}$ thick layer at the front of the sediment to reach uncontaminated material. The scraper only cores into the central portion of the core face to avoid contamination from material along the cylindrical sides of the specimen.

In stage three, a sterile bio-reactor chamber is attached to the BIO chamber. These exchangeable bio-reactors have been previously autoclaved along with the additional culturing equipment, nutrients, and solutions for 40 minutes at $100 \mathrm{kPa}$ and $120^{\circ} \mathrm{C}$. Uncontaminated sediment is scraped from the circular face of the pressure core, collected at the head of the scraper, and dropped into the sterile bio-reactor chamber. For this particular study, the 
concentration of the $\mathrm{NaCl}$ solution used as a buffer is $8 \mathrm{~g} / \mathrm{l}$, and the nutrient is Lysogeny Broth (LB)-Miller formula consisting of $10 \mathrm{~g}$ of tryptone, $5 \mathrm{~g}$ of yeast extract, and $10 \mathrm{~g}$ of $\mathrm{NaCl}$ in one liter of distilled water. The LB-Miller formula is a complex nutrient that prompts the growth of unspecified targets; it is selected for these studies to nourish the greatest breadth of microorganisms.

In stage four, a dissociation and gas-production test is run to recover methane from the hydrate-bearing pressure core specimen remaining in the BIO-chamber. To facilitate the measurement of produced gas during dissociation, the chamber-pressurizing argon gas surrounding the specimen is displaced, at pressure and prior to dissociation, with the laboratorysimulated seawater used to pressurize the PCCTs throughout this study. Water is introduced into the chamber from below, and the water injection continues until water is forced through the uppermost port in the BIO chamber. To measure the volume of residual argon remaining in the chamber, the chamber pressure is briefly increased while measuring the injected water volume required for that pressure increase. Based on the volume response, the residual argon volume is calculated. Expansion of the residual argon volume during depressurization-induced hydrate dissociation is then calculated and subtracted from the overall volume expansion attributed to methane release during dissociation.

Ideally, bio-reactor vessels will either be used to incubate specimens at pressure or will be depressurized in an anoxic environment in which the incubation can be run. Once incubated, the specimens can be examined using a staining or biomarker process to uncover the breadth and function of the biologic communities present in the test sediment. Due to time limitations in this study, the bio-reactor vessels were depressurized at different rates (to study the effect of the rate in pressure change on bio-survivability) and cultured under aerobic conditions at different 
temperatures to examine the dependence of microbial growth on temperature. Depressurizations from $7 \mathrm{MPa}$ to atmospheric pressure are accomplished over one of three time intervals: 2 seconds (i.e., a fast depressurization rate), 1 minute, and 30 minutes (i.e., a slow depressurization rate). The spread-plate method is used to count cells, which grow on 60mm diameter Petri-dishes containing $15 \mathrm{~g}$ of nutrients made of agar $(15 \mathrm{~g} / \mathrm{L})$ and the LB-Miller formula. Dilutions are $10^{-1}$ and $10^{-3}$ and the specimens are cultured in air at atmospheric pressure and temperatures of 4,10 , or $30^{\circ} \mathrm{C} .4^{\circ} \mathrm{C}$ is approximately the temperature at which the cores were stored, $10^{\circ} \mathrm{C}$ is the room temperature during the study period and is close to the $12^{\circ} \mathrm{C}$ in situ temperature, and $30^{\circ} \mathrm{C}$ is the incubator temperature. During incubation, cell growth is recorded periodically by taking photographs.

\section{Experimental Results}

Cores $8 \mathrm{P}$ and $10 \mathrm{P}$ were taken from the upper third of the methane hydrate concentration zone (MHCZ), while core 20P was from the lower third of the MHCZ (see Fujii et al., 2015, and Inada et al., 2015, for additional coring interval information). Testing locations along each pressure core for all PCCT devices are shown in Fig. 2. Device-specific results are given below.

To identify hydrate-rich sections and choose locations for testing, the X-ray scans (Fig. 2) were paired with P-wave velocity data, both measured using the Pressure Core Analysis and Transfer System PCATS through the core liner (Suzuki et al., 2015). The DSC and ESC test location choices (red and yellow outlines in Fig. 2, respectively) were further restricted by their requirement of coherent sections. The BIO subsection was chosen from an adjacent section in which the sediment was transitioning to finer-grained material (grey outline in Fig. 2a).

Not all IPTC sensors were used in every measurement location. In core 8P, the electrical 
conductivity probe failed prior to completing the core. The shear and strength probes were yielding effective stress-dependent results in low-hydrate-saturation sections, as observed in Core 10P (see sections 5.1 and 5.2). For efficiency, and given the absence of effective stress control in the IPTC, these probes were not used in regions of core $8 \mathrm{P}$ where the hydrate saturation was expected to be low. In core 10P, the penetrating strength and electrical conductivity probes were not used in the DSC specimen section to prevent probe penetration holes from compromising the shear strength of the DSC specimen.

\subsection{Instrumented Pressure Testing Chamber}

Fig. 2 shows the IPTC results and measurement locations for cores 8P and 10P, which include silty-sands with high-hydrate saturation (high $S_{h}$ ), and sandy- or clayey-silts with lowhydrate saturation (low $S_{h}$ ). The IPTC results illustrate the correlation between high $S_{h}$ and high wave velocities, high strength and a large electrical conductivity drop with probe penetration into the specimen (See Table 1). The significant difference in stiffness of the high- $S_{h}$ silty-sand sediment relative to the low- $S_{h}$ sandy- and clayey-silts is apparent in the functionality of the IPTC probes:

Compressional Wave Velocity $V_{\underline{P}}$ : The $\mathrm{P}$-wave pinducers produce an acoustic signal with a flat baseline and an abrupt first break when measurements are made in low- $S_{h}$ sandy- and clayey-silts, indicating good contact between the pinducer and sediment. In high- $S_{h}$ silty-sands, it is possible to press the pinducers against the specimen too hard, straining the transducer crystal to the point of generating a large-amplitude, low frequency baseline in the measured waveform from which the acoustic signal's first arrival must be picked.

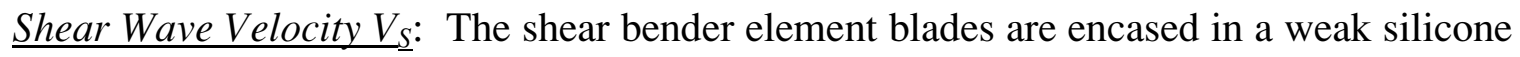
cylinder, allowing the bender tip and front face of the silicone cylinder to contact a solid 
specimen to impart a shear wave. In the relatively soft, low- $S_{h}$ silts and clays, the siliconeencased bender elements can penetrate into the specimen, allowing the vibration of the sides of the cylindrical silicone to also produce a significant $\mathrm{P}$-wave signal that obscures the $\mathrm{S}$-wave arrival. S-wave velocity values in relatively soft, low- $S_{h}$ sediments with no applied effective stress are likely to be overestimates. When pressed against hard, high- $S_{h}$ material, the siliconeencased bender elements are too weak to penetrate the specimen without breaking. The circular front face of the probe produces relatively little P-wave energy, facilitating the S-wave arrival pick.

Strength $\underline{S}_{\underline{u}}$ : Because there is no effective stress applied in the IPTC, the undrained shear strength $S_{u}$ can be estimated from the force $F_{c}$ measured by the cone penetrometer during penetration into the specimen via (Terzaghi et al., 1996):

$$
S_{u}=\frac{q_{c}}{N_{k}}=\frac{F_{c}}{A_{c} \cdot N_{k}}
$$

The cone penetrometer tip resistance $q_{c}$ is the ratio of the measured force $F_{c}$ and the cone's cross-sectional area $A_{c}=22 \mathrm{~mm}^{2}$. The probe constant $N_{k}$ is a function of soil type. Yun et al. $(2011 ; 2006)$ took $N_{k}$ to be $\sim 10$ in previous IPTC deployments, where hydrate appeared as lenses or nodules within fine-grained, relatively soft sediment into which the probe could be inserted its full $\sim 18 \mathrm{~mm}$ travel.

In stiffer, high- $S_{h}$ silty-sands from the Nankai Trough, the cone penetrometer's tip resistance rapidly increases during insertion, but then drops sharply before the full $\sim 18 \mathrm{~mm}$ travel can be completed (Fig. 3). The sharp drop in tip resistance indicates brittle failure as the specimen fractures ahead of the cone. Brittle failure in high- $S_{h}$ silty-sands is also observed in this study by Yoneda et al. (2015). Because cone penetrometers have not been used extensively in hydrate-bearing sands, the empirical parameter $N_{k}$ is chosen based on the work of Beringen et al. 
(1982), who found $N_{k}$ to be in the range of 15-20 in their study of calcareous soils. Using the binding in calcareous soils as an analog for the strengthening behavior of gas hydrate in sands, $N_{k}$ is also taken to be 15-20 in Table 1 , which shows the shear strength $S_{u}$ for the peak tip load in each measured location.

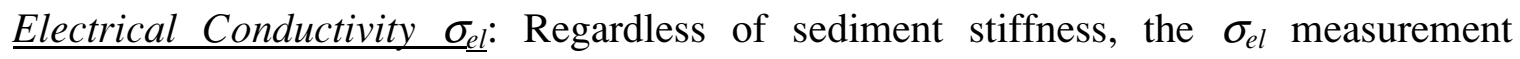
initially decreases as the probe passes from the conductive core-pressurizing fluid into the core itself. An $\sigma_{e l}$ minimum is reached before $\sigma_{e l}$ begins increasing again with continued insertion. The largest $\sigma_{e l}$ range occurs for the high- $S_{h}$ silty-sands. During the measurement of $\sigma_{e l}$ in core $8 \mathrm{P}$ at $190 \mathrm{~cm}$, the $2.1 \mathrm{~mm}$-diameter probe was not strong enough to penetrate the specimen and bent during the attempted insertion.

\subsection{Effective Stress Chamber}

Stress-Volume Response: Fig. 4 shows the complete stress-volume change history of the two tested specimens. Prior to hydrate dissociation, core $8 \mathrm{P}$ is loaded up to an applied stress of $6 \mathrm{MPa}$ and then unloaded back to $3 \mathrm{MPa}$ in order to study the stress-volume response of hydratebearing sediments. The stress-volume responses of this specimen after hydrate dissociation is also measured using several loading-unloading cycles. Core 10P is initially loaded to an applied stress of $3 \mathrm{MPa}$ to conduct permeability and gas production tests. After the hydrate dissociates, core 10P is taken through loading-unloading cycles up to an applied stress of 9MPa. The stressvolume responses provide the compression index $C_{c}$ and recompression index $C_{r}$ (or swelling index) before and after hydrate dissociation for both cores (Table 2).

Water Permeability: Measured differential pressure $\Delta u$ under a constant flux $q$ oscillates with time (Fig. 5A), so the slope of $\Delta u$ integrated over time (Fig 5B) is used as the "mean" differential pressure for computing water permeability based on Eq. 1. Water permeability 
measurements are repeated for three to four different fluid fluxes $q$. Each water permeability value is determined through the regression of a series of measured $q$ vs. $\nabla P / \mu$ data (Fig. 5C).

Measured water permeability values for of the two tested specimens are summarized in Table 2. The permeability increases $\sim 5.3$ times after hydrate dissociation for core $8 \mathrm{P}$ (initial hydrate saturation $S_{h}=0.18$ ), and $\sim 47$ times for core 10P (initial hydrate saturation $S_{h}=0.74$ ). The water permeability in hydrate-free sediment in both cases is similar (tenths of a Darcy, see Table 2); this result highlights the blocking effect of hydrate, lowering the flow permeability of its host sediments when water is the only mobile phase. This comparison can be made here because the water permeability of hydrate-free sediments is measured at a pore pressure of $10 \mathrm{MPa}$ for which the specimen is essentially water-saturated. As the pore pressure is lowered and residual gas expands, the system becomes more analogous to natural systems during gas production from hydrate in which gas and water are both mobile and relative permeability must be considered for water and gas (see section 5.4).

Gas Production: Gas production tests for both specimens are conducted using depressurization. Although specimens are immersed in saline water throughout the collection, storage, and testing process, measured $P-T$ signatures evolved along the phase boundary for pure water (Fig. 6A,B). This is likely due to hydrate crystals directly contacting newly produced fresh water from hydrate dissociation. Fig. 6C,D shows the collected methane gas volume during the production tests. The methane production rates in the first $\sim 4$ minutes for both specimens are almost identical, probably constrained by the maximum flux through a small outlet (1/8-inch stainless steel tubing with an inner diameter of $1.75 \mathrm{~mm})$. After $\sim 250$ seconds, the production rate slows down for both specimens. Eventually, $\sim 1.4 \mathrm{~L}$ methane is collected from core $8 \mathrm{P}$ and $\sim 7.0 \mathrm{~L}$ from core $10 \mathrm{P}$. 
Hydrate saturation $S_{h}$ is computed from the amount of gas extracted as:

$$
S_{h}=\frac{\frac{V_{g}}{n V_{c}}-\chi_{C_{4}}}{c_{0} \beta-\chi_{C_{4}}}
$$

where $V_{g}$ is the volume of gas collected at atmospheric pressure, $n$ is the porosity, $V_{c}$ is the specimen volume, $\chi_{\mathrm{CH} 4}$ is the methane solubility in water, taken to be 2.52 and $2.55 \mathrm{~L} / \mathrm{L}$ for the 8P and 10P specimens respectively (Fujii et al., 2015, $c_{o}$ is the cage occupancy, taken to be 0.9425 based on directly measuring a hydration number of 6.1 for the ATC-1 site (Kida et al., 2015), and $\beta=172$ is the gas volume expansion factor (Kida et al., 2015).

\subsection{Direct Shear Chamber}

Stress-Volume Response: Fig. 7A shows the relaxation behavior after the initial load step in hydrate-bearing core $20 \mathrm{P}$ prior to dissociating the hydrate. It can be seen that the total relaxed strain during each displacement step gradually decreases. As with the ESC, the stress-volume response is also used to calculate the compression indices $C_{c}$ and $C_{r}$ (See Table 3).

Undrained Shear Strength \& Friction Angle: Fig. 7B is the measured shear strength in hydrate-bearing core 20P, calculated as $\tau=H / 2 A-u_{\text {cell }}$ where $H$ is the applied force on the horizontal loading piston and $A$ is again the cross-sectional area of the core specimen. The shearing load is applied in displacement steps of one millimeter each, and the system is left to relax before the next displacement step. Blue squares and green dots represent measurements made before and after specimen relaxation, respectively. Fig. 8 shows the mobilized friction $\varphi$ angle as a function of displacement during the shear-strength tests carried out before and after hydrate dissociation.

Compressional Wave Velocity: Fig. 9 shows P-wave signals collected during hydrate dissociation. To test whether gas bubbles produced during hydrate dissociation could be 
responsible for the observed amplitude loss, the water saturation $S_{w}$ is related to the P-wave attenuation using an empirical relationship in which the attenuation $1 / Q_{P}$ is related to the waveform amplitude $A$ by (Murphy, 1982; Santamarina et al., 2001):

$$
A=A_{1} e^{\frac{-1}{Q_{P}} \pi \cdot f \cdot V_{p} \cdot L},
$$

where $f$ is the $\mathrm{P}$-wave frequency, $V_{P}$ is the $\mathrm{P}$-wave velocity, and $L$ is the specimen length. $A_{l}$ is the amplitude in the absence of attenuation, taken from the waveform at $u_{\text {cell }}=5 \mathrm{MPa}$. The waveform amplitude at $u_{\text {cell }}=4.7 \mathrm{MPa}$ is as expected for a gas saturation of 0.15 .

Gas Production: The dissociation results for the procedure described in section 3.2 are collected in Table 3. Like the ESC results (Fig. 6A), dissociation in the DSC is observed to primarily follow the phase boundary for pure water.

\subsection{BIO-Chamber}

Table 4 contains the observed cell counts, growth times and specimen histories for the biological test sequence. We observe colony-forming units CFUs 43 hours after introducing nutrient solutions containing pressure core material to the agar plates incubated at $30^{\circ} \mathrm{C}$. The largest colonies are on the $10^{-3}$ dilution plate supporting material from the fast depressurization, reaching $2-4.7 \mathrm{~mm}$ in diameter within their $\sim 2$ day incubation period.

The remaining plates require 11 to 18 days to grow observable CFUs, and are observed for 32 days. Given these longer growth periods, final colony sizes range from $1-10 \mathrm{~mm}$ in diameter. As shown in Fig. 10, the colonies have a variety of colors, sizes and edge types. This suggests a range of microbe species have been successfully cultured, even using oxic, atmospheric pressure conditions. Microbe identification is not included in this proof-of-concept study intended to show that culturable material can be acquired at pressure from pressure-core sediments. 
Once the biologic samples are collected, the BIO chamber with the remaining hydratebearing sediment is depressurized to measure the specimen's hydrate content. Approximately three liters of gas were produced from this core $8 \mathrm{P}$ specimen. For a specimen porosity of 0.475 , the average hydrate saturation in the specimen is 0.27 . This value is an upper bound, because even though the presence of residual argon gas is accounted for in the calculation, an underestimate of this residual volume would overestimate the volume of methane produced by the dissociating hydrate and lead to an overestimate of the hydrate saturation.

\section{Analyses and Discussion}

Here we discuss PCCT results in the context of index properties, morphology-based analytical models and complimentary studies made during this MH21 Nankai Trough program. Correlations with modeling predictions and complimentary measurements provide insight into the in situ environment and the condition of the pressure cores themselves.

\subsection{Small-strain properties: wave velocities and moduli}

Velocity measurements have been used extensively to study the pore-scale distribution of hydrate within sands (e.g. Choi et al., 2014; Lee et al., 2013; Priest et al., 2009), estimate the small-strain bulk-, shear- and compressional-moduli as well as the Poisson's ratio (Helgerud et al., 2009; Lee et al., 2010a), and link seismic and well log measurements to in situ hydrate saturations (e.g. Fohrmann and Pecher, 2012; Hunter et al., 2011; Shankar and Riedel, 2014; Shelander et al., 2012). In this study, compressional and shear wave velocities, $V_{p}$ and $V_{s}$ respectively, are collected at zero effective stress in the IPTC, and over a range of effective stresses in the DSC.

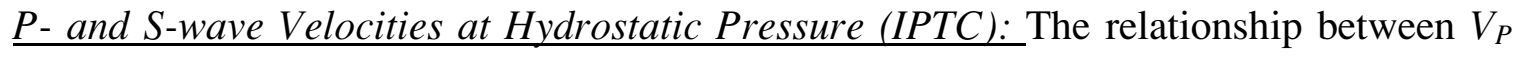


and $V_{S}$ in the high-S $S_{h}$ silty-sand section of $8 \mathrm{P}$ (solid circles for $V_{P}$ and $V_{S}$ in Fig. 2) suggests the core contains non-cementing gas hydrates. Using the Gassmann formulation, we can estimate $V_{P}$ from $V_{S}$ (Santamarina et al., 2001; Santamarina and Ruppel, 2008):

$$
\begin{aligned}
& V_{P}^{2}=V_{S}^{2}\left(\frac{1-v_{s k}}{1-2 v_{s k}}+\frac{4}{3}\right)+\frac{1}{\rho_{\text {mix }}}\left(\frac{1-n}{B_{m}}+n\left(\frac{S_{h}}{B_{h}}+\frac{1-S_{h}}{B_{w}}\right)\right)^{-1}, \\
& \rho_{\text {mix }}=\rho_{m}(1-n)+\rho_{h} n S_{h}+\rho_{w} n\left(1-S_{h}\right),
\end{aligned}
$$

where $v$ is the Poisson's ratio for the sediment skeleton, $n$ is the sediment porosity, $\rho$ is density, and $B$ is bulk modulus. The subscript "mix" refers to the sediment/hydrate/water mixture, and the subscripts $m, h$ and $w$ refer to the sediment minerals, hydrate and water, respectively. Following Santamarina and Ruppel (2010), we take $v_{s k}$ to be 0.1 for $S_{h}<0.4$, and 0.2 for $S_{h}>0.5$. Remaining parameters are taken from Table 5. From the measured $V_{S}$ in the high- $S_{h}$ silty-sand section of $8 \mathrm{P}$, the predicted $V_{P}$ from Eq. 6 within $\sim 7 \%$ of the measured $V_{P}$ (solid circles for $V_{P}$ and $V_{S}$ in Fig. 2, see also Table 1). Fig. 11 presents the measured $V_{P}$ and $V_{S}$ results in comparison with the four homogeneous hydrate morphology models described by Dvorkin et al. (2000), as well as the patchy hydrate morphology model by Berryman (1995). Measured wave velocities are in agreement with hydrate nucleation on mineral surfaces (low hydrate saturation), followed by growth into the pore space to eventually contact neighboring particles as hydrate becomes load bearing (high hydrate saturation).

In the low- $S_{h}$ regions, Eq. 6 overpredicts the measured $V_{P}$ by $15-27 \%$. We attribute this to an overestimate of the measured shear velocities in the low- $S_{h}$ regions due to P-wave energy obscuring the shear wave's first arrival. Even if the S-wave arrival were clear, because the IPTC is a hydrostatic chamber with no applied effective stress, the measured wave velocities in sections where $S_{h}<\sim 50 \%$ are expected to be low relative to in situ values.

P-wave Velocity Dependence on Effective Vertical Stress (DSC): Hydrate-bearing cores 
recovered from the subsurface inevitably experience unloading due to the removal of the overburden sediments during drilling. Only very limited stress, if any, may get locked within the sediments due to friction between the sediment and core liner. The DSC subsection of core 10P has a low $S_{h} \sim 0.13$, and $V_{P}$ should depend strongly on effective stress for $S_{h}<\sim 50 \%$ (Lee et al., 2010a). This stress dependence and the additional impact of long-term core storage in the absence of effective stress are evident when comparing $V_{P}$ measurements made by the DSC, IPTC and the Pressure Core Analysis and Transfer System PCATS (Fig. 12).

As shown in Fig. 12, the expected $V_{P}$ as the specimen undergoes the rapid unloading that would occur during collection (black squares) is higher than $V_{P}$ measured using PCATS (Suzuki et al., 2015) one week after collecting core 10P (red star in Fig. 12) and $V_{P}$ measured in the IPTC (red open circle in Fig. 12) 27 weeks after the PCATS measurement. The IPTC measures $V_{P}$ by direct contact with the sediment, while PCATS measures $V_{P}$ through the core liner. Although this difference in measurement technique likely causes a discrepancy between IPTC and PCATS results, we attribute the majority of the drop in $V_{P}$ to core material relaxation and aging, as is demonstrated to occur in the Anelastic Strain Recovery (ASR) study (Nagano et al., 2015). Core relaxation and aging weakens the sediment fabric, further reducing the constrained stiffness, $M$, and hence the compressional wave velocity (Eq. 9, below). Restoring the applied stress F/A $u_{\text {cell }}$ to the specimen in the DSC reconsolidates the core material, increasing $V_{P}$.

In Fig. 12, the shift from a rapidly increasing velocity with increasing applied stress (filled black circles in Fig. 12) to a slower increase suggests the specimen has returned to its in situ effective stress near 2.8MPa. The compressibility after hydrate dissociation (not shown), again shows a pre-consolidation value of $3 \mathrm{MPa}$ because the specimen is loaded during dissociation. The in situ $\sigma_{v}$ ' calculated from well $\log$ data for this core is estimated to be 
2.32MPa from logging results of the 2011 Nankai Trough campaign.

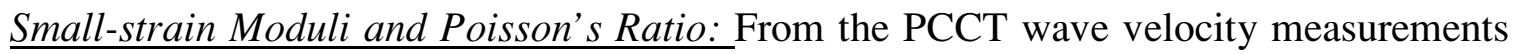
and bulk density information, we estimate small-strain moduli and Poisson's ratio from the following relations (Mavko et al., 1998):

$$
\begin{aligned}
& \text { Bulk stiffness: }=\rho_{\text {mix }} \cdot\left(V_{P}^{2}-\frac{4}{3} V_{S}^{2}\right), \\
& \text { Constrained stiffness: } M=\rho_{\text {mix }} \cdot V_{P}^{2}, \\
& \text { Shear stiffness: } \quad G=\rho_{\text {mix }} \cdot V_{S}^{2}, \\
& \text { Poisson's Ratio: }=\frac{1}{2} \cdot \frac{V_{P}^{2}-2 V_{S}^{2}}{V_{P}^{2}-V_{S}^{2}} .
\end{aligned}
$$

These results are gathered in Table 6.

\subsection{Large-strain properties: shear strength and friction angle}

Shear Strength: In the high- $S_{h}$ silty-sands in core 8P, the undrained shear strength $S_{u}$ ranges from 1.7 to $1.9 \mathrm{MPa}\left(N_{k}=20\right)$ or 2.3 to $2.6 \mathrm{MPa}\left(N_{k}=15\right)$ for $S_{h}=.49$ and .58 , respectively. The cone penetrometer results are in agreement with results measured in a triaxial apparatus by Yoneda et al. (2015) on a separate Nankai Trough core subsection. Agreement between strength measurements made with and without an applied stress indicates the sediment strength in the high- $S_{h}$ silty-sands is controlled primarily by the presence of hydrate rather than the state of stress. This is not the case in the low- $S_{h}$ sediment.

In low- $S_{h}$ sediment, the undrained shear strength does not peak during probe insertion as it does in the high- $S_{h}$ silty-sands. Instead, $S_{u}$ rises until the penetrometer stops moving, having reached its full travel, after which the pore pressure relaxes (Fig. 3). Taking the maximum $S_{u}$ as a lower bound on the in situ value, the measured strength in the low- $S_{h}$ regions is at or below the expected strength of normally consolidated, uncemented clay given by (Mesri, 1989):

$$
S_{u}=0.22 \cdot \sigma_{v}^{\prime},
$$


where the vertical effective stress, $\sigma_{v}{ }^{\prime}$, or overburden, is $2.27 \mathrm{MPa}$ and 2.32 MPa for cores $8 \mathrm{P}$ and 10P, respectively (open circles for $S_{u}$ in Fig. 2). Since there is no applied effective stress in the IPTC, $\sigma_{v}{ }^{\prime}=0$, results below values predicted by Eq. 12 are expected, particularly for silty and sandy sediments.

The first direct shear measurement made on hydrate-bearing pressure core material was accomplished on the DSC subsection of core 20P, which has $S_{h}=0.27$. The undrained peak shear result is within the range of published values given by Yoneda et al. (2015). The shear strength, measured with an applied stress of 3MPa, drops by $\sim 30 \%$ after hydrate dissociation. The residual shear strength is much less sensitive to the presence of hydrate, decreasing only $14 \%$ after hydrate dissociation.

Mobilized Friction Angle: The peak friction angle drops by $\sim 37 \%$, a significant response to hydrate dissociation, but the residual friction angle is much less sensitive to the presence of hydrate (Fig. 8) (Jung et al., 2012a). The peak and residual friction angles of core 20P after hydrate dissociation are likely controlled by the type and concentration of fine-grained sediment (fines) in the specimen (Fig. 8B). Although the impact of fines can be significant, the friction angle is not simply proportional to the fines content. For example, friction angles in most pure quartz sands are $38-40^{\circ}$, but increase up to $44-49^{\circ}$ when $5 \mathrm{wt} \%$ bentonite (smectite) is added, then decrease to $27-31^{\circ}$ when the bentonite content reaches $20 \mathrm{wt} \%$ (Mollins et al., 1999). Note in Fig. 8B that the DSC subsection of core 20P contains 12-15 wt $\%$ smectite, and $69-70 \mathrm{wt} \%$ quartzitic sands (Egawa et al., 2015).

\subsection{Electrical conductivity}

Relative to the saline water used to hold hydrostatic pressure on the measured cores, hydrate and sediment grains are electrical insulators. The measured conductivity drops as the 
conductivity probe penetrates the core and the probe tip transitions from being surrounded by a conductive pressurization fluid to being increasingly surrounded by low-conductivity material. Conductivity can drop further in high- $S_{h}$ silty-sands where conductive pore fluid is replaced by insulative gas hydrate (Lee et al., 2010b; Pearson et al., 1983; Spangenberg and Kulenkampff, 2006).

The measured electrical conductivity $\sigma_{e l}$ is a function of the pore fluid conductivity $\sigma_{f}$ as well as the porosity $n$ and properties of the host sediment. Archie's law (Archie, 1942):

$$
\sigma_{e l}=\frac{\sigma_{f}}{a n^{-m}},
$$

is often used to predict conductivities in marine sediment, and can be used here to anticipate the measured conductivity drop as the probe passes from the salt water surrounding the specimen and into the sediment itself. Taking $\sigma_{f}=3.09 \mathrm{~S} / \mathrm{m}$ as measured for the pressurizing water via a YSI conductivity meter, and the Archie parameters $\alpha=1$ and either $m=2-2.4$ from IODP studies of the Nankai Trough (Conin et al., 2011; Reuschle, 2011) or $m \sim 2$ based on estimates for hydrate-bearing sediments (Spangenberg, 2001), the predicted $\sigma_{s}$ for core $8 \mathrm{P}$, with a measured porosity, $n$, of $\sim 0.49$, is $0.56-0.74 \mathrm{~S} / \mathrm{m}$. For core $10 \mathrm{P}$, with a measured porosity $n$ of $\sim 0.46$, the anticipated specimen $\sigma_{s}$ is $0.48-0.66 \mathrm{~S} / \mathrm{m}$. We do not observe such low conductivities because with continued electric probe insertion, the measured conductivity tends to stop decreasing and begin increasing. This increase, which is particularly noticeable in the high- $S_{h}$ silty-sands, may be because the wider shoulder of the probe enters the sediment, spreading the sediment and allowing high-conductivity core-barrel water to penetrate to the probe tip, preventing the probe from measuring the true in situ conductivity. This process is consistent with our observations of brittle fracture during insertion of the cone penetrometer (Fig. 3).

\subsection{Water Permeability}


In natural hydrate systems, permeability governs fluid flow processes, affects methane supply and thus methane hydrate accumulation and distribution, and determines gas production efficiency. Permeability is thus one of the most important properties for natural hydrate-bearing sediments, yet very little data is available, primarily due to experimental challenges in preventing naturally-occurring hydrate from dissociating or dissolving during the collection, storage and measurement process. Our study provides direct, soft-walled permeameter measurement of the water permeability of naturally-occurring hydrate-bearing sediments held continuously within the hydrate-stability field.

$\underline{S}_{h}$ Effect on Water Permeability: The presence of hydrate decreases sediment porosity, increases hydraulic flow tortuosity, and thus, decreases the water permeability. The water permeability of Nankai Trough cores is measured both with and without hydrates under in situ stress and pore pressure conditions. The hydrate-saturation-dependent water permeability, relative to the hydrate-free case, in Nankai Trough cores is shown in Fig. 13, together with four morphology-based models. Results obtained in this study suggest hydrate grows into the pore space and avoids grain contacts, as is also concluded from the wave velocity analysis (Fig. 11).

In the sand-rich, highly hydrate-saturated specimens $\left(S_{h} \geq 0.7\right)$, permeability is largely controlled and limited by the presence of hydrate; the ESC result of $6.12 \mathrm{mD}$ (core $10 \mathrm{P}-2, S_{h}=$ 0.74 ) is in good agreement with the shipboard permeability result of $19 \mathrm{mD}$ (core $18 \mathrm{P}-5, S_{h}=0.7$ ) measured using the PCATS triaxial system (Priest et al., 2015) and the $19.1 \mathrm{mD}\left(13 \mathrm{P}-2, S_{h}=\right.$ 0.75) measured on a core preserved in liquid nitrogen (Konno et al. 2015). As expected, at lower hydrate saturations $\left(S_{h} \leq 0.2\right)$, permeability results vary dramatically between specimens in response to variations in index properties such as sediment porosity and grain size (see Table 2 and Priest et al., 2015). 


\section{Estimation of Relative Water Permeability in the Presence of Gas: The water}

permeability in core $8 \mathrm{P}$ in hydrate-free sediments after the production test is measured in the ESC under different fluid pressures and hence different water/gas saturations. Results, plotted in terms of water saturation $S_{w}$ in Fig. 14, show the presence of gas reduces the water permeability, but less effectively than does the presence of hydrate itself (Fig. 13). The following assumptions are made to estimate the relative water permeability curve in this study: (1) the initial water saturation after hydrate dissociation is assumed to be 0.55 , based on results of recoverable gas analysis for sediment with $S_{h}=0.15-0.20$ (note: $S_{h}=0.18$ in core 8P) (Jang and Santamarina, 2011); (2) the residual water saturation $S_{r w}$ in this specimen is assumed to be the water content measured after complete depressurization of the specimen, which is 0.16 ; (3) the pressure dependent volume change of methane gas follows a modified Peng-Robinson equation of state (Stryjek and Vera, 1986). Pressure and volume are inversely related, meaning the higher the pressure, the smaller the gas volume and higher the water saturation; and (4) the loss of gas within the sediments during the permeability measurement is neglected. Note that permeability is measured at an extremely low constant total flux $q=1 \mathrm{ml} / \mathrm{min}$ and each measurement takes $\sim 100$ seconds, so the total loss of pore constituents (water and gas) during each measurement is $\sim 1.6 \mathrm{ml}$, which accounts for $<0.1 \%$ by volume of the core's total pore space $\sim 2000 \mathrm{ml}$. As shown in Fig. 14, results are best fitted by an empirical exponential model (Brooks and Corey, 1964).

\subsection{Thermal Properties}

Although no thermal properties are directly measured in this PCCTs study, they can be assessed based on the total temperature drop $\Delta T$ of the BIO chamber and hydrate-bearing core during hydrate dissociation due to the endothermic heat $H_{\text {Diss }}$ and the geometrical and geophysical properties of the system: 
where $L$ is the latent heat, $\rho$ is the density, $V$ is the volume, and $c$ is the specific heat capacity. Subscripts $s s, q, w$, and $h$ represent the stainless steel, quartz, water, and hydrate components in the system. Table 7 lists the values from the BIO chamber as an example. The estimated temperature change due to hydrate dissociation in the $\mathrm{BIO}$ chamber is $-0.19^{\circ} \mathrm{C}$, which is in close agreement with the measured temperature change of $-0.13^{\circ} \mathrm{C}$. This agreement underscores the reliability of published thermal properties for gas hydrate.

\subsection{Settlement during Gas Production: Fines Migration}

The mechanical and hydrological properties of soils can be altered significantly if the soil grains themselves are mobilized. A critical concept, even for generally coarse-grained hydratebearing sands, is the impact of fines migrating within the sediment in the direction of fluid flow (i.e., toward the depressurization boundary) during gas production. Even at very low fines content, fracture formation and sediment collapse can occur where fines have been swept away. Conversely, permeability shutdown can occur where the fines collect downstream (Jung et al., 2012b). As shown in Fig. 4a, core settlement due to hydrate dissociation in core $8 \mathrm{P}$, for which the depressurization boundary is sealed and escaping gas and fluid has to pass through a $4.7 \mathrm{~mm}$ thick porous stone, was only $0.09 \mathrm{~mm}$. This corresponds to a $0.02 \%$ vertical strain. In contrast, core $10 \mathrm{P}$ is depressurized at the top boundary, which is open to an upper, fluid-filled cavity in the chamber. This allows escaping gas, fluid, and sediment to migrate around, rather than through, the upper porous stone. Because the porous stone has a diameter of $50.8 \mathrm{~mm}$ and the inner diameter of the core holder is $52.6 \mathrm{~mm}$, sediment could have a gap as wide as $1.8 \mathrm{~mm}$ through which to pass. The total settlement caused by hydrate dissociation is $1.5 \mathrm{~mm}$, or $2.4 \%$ vertical strain for core 10P. At the end of the test, we found a significant volume of fine particles 
had bypassed the porous stone and been flushed into the upper cavity in the chamber during gas production from the top boundary. The sediment re-settled on top of the porous stone, forming a nearly $5 \mathrm{~mm}$-thick mud cake. This result highlights that significant sediment deformation can be induced by fines migration during gas production; sturdy, large-deformation resisting filters are needed with an opening size less than $\sim 5$ times the migratory particle diameter (Valdes and Santamarina, 2007).

\subsection{Biological test}

Cell counts in this study are lower than those of previous studies (Fig. 15); in part, this may be due to factors related to the collection and measurement strategies. In this proof-ofconcept study, we counted microorganisms that survive depressurization and grow in an oxic incubation environment. The differences in pressure, temperature and oxygen levels between the in situ and laboratory conditions can be lethal to some species of microorganisms. Moreover, even for the microbes that survive, less than $1 \%$ of the total number of microorganisms are culturable (Madigan et al., 2009). In contrast, previous studies using staining methods are able to include all types of microorganisms, both dead and alive.

Cultured microorganisms show temperature-dependent growth. The in situ sediment temperature is $\sim 12^{\circ} \mathrm{C}$, so the cultured microorganisms like mesophiles, may prefer warmer temperatures. There is no obvious dependence of colony-forming unit CFU count on depressurization rate, with the trends observed at $10^{-1}$ dilution being opposite those observed for $10^{-3}$ dilution.

\section{Conclusions}

Pressure core characterization tools PCCTs allow the study of minimally-disturbed, 
naturally-occurring hydrate-bearing sediments by maintaining the recovered specimens within methane hydrate stability pressure and temperature conditions throughout the experimental program. PCCT devices are designed to measure the most relevant parameters necessary for borehole stability and gas production analyses and coupled hydro-thermo-chemo-mechanical reservoir simulators.

A broad set of PCCTs was deployed for the first time in Japan for characterizing pressure cores recovered from the Nankai Trough. Data interpretation benefited from complementary index properties and mineralogy data, and parallel measurements made within separate PCCT chambers and other devices. Salient observations follow:

The tested Nankai Trough sediments consist of clayey-silt and sandy-silt layers interbedded with frequent occurrences of silty-sand layers. Hydrates concentrate in the siltysands, where pore-space hydrate saturations range between $S_{h}=0.15$ and 0.74 . In these layers, compressional and shear-wave velocities are in agreement with hydrate nucleation on mineral surfaces, followed by growth into the pore space to eventually connect grains together. In these layers, cone penetrometer measurements of undrained shear strength $S_{u}$ made with no effective stress agree with triaxial shear tests made on core material of similar hydrate saturation: $S_{u}$ scales primarily with hydrate saturation rather than effective stress as hydrate binds the sediment together in highly hydrate-saturated silty-sands. Both the penetrometer and electrical conductivity measurements indicate these high $S_{h}$ sediments are prone to fracturing in response to probe penetration.

The clayey- and sandy-silt layers have hydrate saturations lower than $S_{h} \approx 0.30$; the mechanical properties in these sediments are primarily controlled by effective stress and are affected by clay content. The compressional wave velocity $V_{P}$ measured at zero effective stress 
in the Pressure Core Analysis and Transfer System PCATS one week after collecting the core is slightly higher than the P-wave velocity measured at zero effective stress in the IPTC 28 weeks after collection. The effects of expansion and relaxation-induced aging during storage at zero effective vertical stress are reversed when the in situ effective vertical stress is reapplied.

The direct shear test of the hydrate-bearing clayey-sand specimen with $S_{h}=0.27$ shows that the peak friction angle drops by $30 \%$ after hydrate dissociation, yet, the residual friction remains nearly unchanged. The low residual friction angle $\varphi_{\text {res }}=25^{\circ}$ confirms the strong effect that clay content (in this case, $12-15 \mathrm{wt} \%$ smectite) can exert on shear resistance.

Temperature changes during dissociation in the BIO chamber can be adequately modeled using published latent heat and specific heat capacity values for the different system components. The agreement between measured and predicted thermal changes confirms the effectiveness of simple mass-averaging for the analysis of thermal changes during dissociation.

Flexible-wall permeameter measurements are conducted on a hydrate-bearing pressure core specimen before and after hydrate dissociation. The water permeability in the presence of hydrate relative to that in the hydrate-free sediment $k_{r}$ is a function of hydrate saturation as predicted with physical models where hydrate forms preferentially in the largest pores. During dissociation, the relative permeability of water can be related to the water saturation using the model by Brooks and Corey (1964); the presence of gas during dissociation reduces water permeability and limits the gain in permeability associated with the reduction in solid hydrate mass.

Sediments contract during depressurization-driven dissociation. Volume contraction is aggravated by fines migration and removal, i.e., fines production. Deliberate steps must be taken to prevent fines migration/removal in laboratory tests as well as field production studies. Screens 
must be able to accommodate large deformations; filters with an opening size less than $\sim 5$ times the characteristic size of migratory particles should prevent loss of fines.

Uncontaminated, biologically-active samples can be successfully acquired for biological studies under anaerobic conditions and within hydrate PT-stability. Specimens from the Nankai Trough show the presence of viable cells; preliminary tests show no influence of depressurization rate, but growth rates are temperature dependent.

The study of Nankai Trough specimens reported here documents the evolving methodology for comprehensively characterizing hydrate-bearing sediments. Data gathered with pressure core characterization tools play a central role, but additional information is gained from borehole logging measurements (see other manuscripts in this special issue) and through post decompression sediment analyses, including index properties. Finally, all data are considered within the framework of physical models and correlations that reflect worldwide sediment data. This methodology provides adequate estimates of parameters necessary for reservoir analyses and simulators.

\section{Acknowledgements}

This study benefitted from the experimental assistance of Efthymios Papadopoulos (Georgia Tech), David Mason, Emile Bergeron (USGS), as well as discussions with Yusuke Jin, Masato Kida, Kosuke Egawa, and Takuma Ito (AIST). PCCTs were developed with funding to Georgia Tech from the DOE/ Chevron Joint Industry Project (JIP), with additional funds from the Joint Oceanographic Institutions, Inc. The JIP also funded the Georgia Tech participation in Sapporo. USGS participation in Sapporo was funded through a technical assistance agreement with Chevron (TAA-12-2135/CW928359). Some USGS developments on the IPTC were funded 
under Interagency Agreement DE-FE0002911 with the U.S. Department of Energy, with additional support from the U.S. Geological Survey. Core acquisition and Japanese participation in this study was supported by the Research Consortium for Methane Hydrate Resources in Japan (MH21 Research Consortium) to carry out Japan's Methane Hydrate R\&D Program conducted by the Ministry of Economy, Trade and Industry (METI). 


\section{Tables}

Table 1. IPTC core characterization. Measured results include compressional- and shear-wave velocity, $V_{P}$ and $V_{S}$, respectively, undrained shear strength $S_{u}$ and electrical conductivity $\sigma_{e l}$. Porosity $n$ and hydrate saturation $S_{h}$ assume hydrate is concentrated in the silty-sandsa . Saturations in finer-grained material $^{\mathrm{b}}$ assume hydrate is uniformly distributed within the measured section, and likely overestimates the location-specific $S_{h}$. Predictions for $V_{P}$ based on the measured $V_{S}$ and Eq. 6 are given for the highhydrate-saturation locations ${ }^{\mathrm{c}}$.

\begin{tabular}{|c|c|c|c|c|c|c|c|}
\hline Core & Location $[\mathrm{cm}]$ & $n[-]$ & $S_{h}[-]$ & $V_{P}[\mathrm{~m} / \mathrm{s}]$ & $V_{S}[\mathrm{~m} / \mathrm{s}]$ & $S_{u}[\mathrm{MPa}]$ & $\sigma_{e l}[\mathrm{~S} / \mathrm{m}]$ \\
\hline \multirow[t]{6}{*}{$8 \mathrm{P}$} & 217.38 & 0.489 & $0.33^{\mathrm{b}}$ & 1500 & $<444$ & $0.153-0.204$ & $2.88-3.09$ \\
\hline & 203.79 & 0.448 & $0.58^{\mathrm{a}}$ & $\begin{array}{l}2760 \\
2575^{\mathrm{c}}\end{array}$ & 956 & $1.923-2.564$ & $2.19-3.09$ \\
\hline & 190.20 & 0.448 & $0.49^{\mathrm{a}}$ & $\begin{array}{l}2302 \\
2373^{c}\end{array}$ & 861 & $1.703-2.270$ & - \\
\hline & 176.61 & 0.475 & $0.27^{b}$ & 1521 & - & $0.618-0.824$ & - \\
\hline & 163.02 & 0.475 & $0.27^{\mathrm{b}}$ & 1511 & - & $0.469-0.626$ & - \\
\hline & 149.43 & 0.475 & $0.27^{b}$ & 1448 & - & $0.082-0.109$ & - \\
\hline \multirow[t]{3}{*}{$10 \mathrm{P}$} & 143.13 & 0.461 & $0.15^{\mathrm{b}}$ & 1513 & $<488$ & $0.019-0.026$ & $2.96-3.09$ \\
\hline & 129.54 & 0.461 & $0.15^{\mathrm{b}}$ & 1582 & $<532$ & $0.285-0.380$ & $2.77-3.09$ \\
\hline & 115.95 & 0.461 & $0.15^{\mathrm{b}}$ & 1587 & $<504$ & - & - \\
\hline
\end{tabular}


Table 2. ESC measured results, before, during and after hydrate dissociation. Water permeability is given in milli-Darcy $(\mathrm{mD})$. To convert to $\mathrm{m}^{2}$, multiply by $9.87 \times 10^{-16}$.

\begin{tabular}{|c|c|c|c|}
\hline & Properties & Core $8 \mathrm{P}$ & Core $10 \mathrm{P}$ \\
\hline \multirow{6}{*}{ 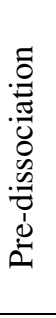 } & Compression index, $C_{c}[-]$ & 0.608 & 0.407 \\
\hline & Recompression index, $C_{r}[-]$ & 0.065 & 0.047 \\
\hline & Water permeability, $k[\mathrm{mD}]$ & 128.28 & 6.12 \\
\hline & Coef. of volume compressibility, $m_{v}\left[\mathrm{~m}^{2} / \mathrm{MN}\right]$ & 0.06 & 0.012 \\
\hline & Coef. of consolidation, $c_{v}\left[\mathrm{~m}^{2} / \mathrm{s}\right]$ & $5.88 \times 10^{-7}$ & $7.34 \times 10^{-7}$ \\
\hline & Initial height, $H_{0}[\mathrm{~mm}]$ & 45.25 & 71.0 \\
\hline \multirow{4}{*}{ 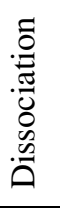 } & Volume of extracted gas, $V_{g}[\mathrm{cc}]$ & 1366 & 6952 \\
\hline & Hydrate saturation, $S_{h}[-]$ & 0.18 & 0.74 \\
\hline & Settlement, $\delta[\mathrm{mm}]$ & 0.09 & 1.5 \\
\hline & Axial strain change during dissociation, $\Delta \varepsilon_{z}[-]$ & $2 \times 10^{-4}$ & $2.4 \times 10^{-2}$ \\
\hline \multirow{6}{*}{ 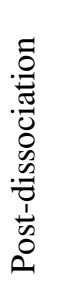 } & Compression index, $C_{c}[-]$ & 0.250 & 0.109 \\
\hline & Recompression index, $C_{r}[-]$ & 0.034 & 0.023 \\
\hline & Water permeability, $k[\mathrm{mD}]$ & 674.23 & 289.98 \\
\hline & Coef. of volume compressibility, $m_{v}\left[\mathrm{~m}^{2} / \mathrm{MN}\right]$ & 0.005 & 0.004 \\
\hline & Coef. of consolidation, $c_{v}\left[\mathrm{~m}^{2} / \mathrm{s}\right]$ & $3.47 \times 10^{-5}$ & $2.7 \times 10^{-5}$ \\
\hline & Specimen final height, $H_{f}[\mathrm{~mm}]$ & 33.6 & 60.2 \\
\hline
\end{tabular}


Table 3. DSC measured results before, during and after hydrate dissociation.

\begin{tabular}{|c|c|c|c|c|}
\hline & Properties & $8 \mathrm{P}$ & $10 \mathrm{P}$ & $20 \mathrm{P}$ \\
\hline \multirow{7}{*}{ 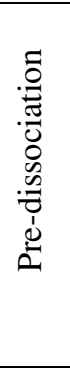 } & Coef. of volume compressibility, $m_{v}\left[\mathrm{~m}^{2} / \mathrm{MN}\right]$ & 0.108 & 0.083 & 0.038 \\
\hline & Coef. of consolidation, $c_{v}\left[\mathrm{~m}^{2} / \mathrm{s}\right]$ & $8.8 \times 10^{-7}$ & $4.4 \times 10^{-6}$ & $9.0 \times 10^{-7}$ \\
\hline & Peak shear strength, $\tau[\mathrm{MPa}] @ \sigma^{\prime}=3 \mathrm{MPa}$ & & & 2.20 \\
\hline & Peak friction angle, $\varphi_{\text {peak }}\left[{ }^{\circ}\right]$ & & & 36 \\
\hline & Residual friction angle, $\varphi_{\text {res }}\left[^{\circ}\right]$ & & & 27 \\
\hline & Wave velocity $\left(@ \sigma^{\prime}=3 \mathrm{MPa}\right), V_{p}[\mathrm{~m} / \mathrm{s}]$ & & 1890 & \\
\hline & Initial height, $H_{0}[\mathrm{~mm}]$ & 60.0 & 117 & 160 \\
\hline \multirow{4}{*}{ 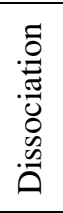 } & Volume of extracted gas, $V_{g}[\mathrm{cc}]$ & 2620 & 4330 & 5030 \\
\hline & Hydrate saturation, $S_{h}[-]$ & 0.21 & 0.15 & 0.27 \\
\hline & Settlement, $\delta[\mathrm{mm}]$ & 2.5 & 4.58 & 3.68 \\
\hline & Axial strain during dissociation, $\varepsilon_{v}[-]$ & $4.8 \times 10^{-2}$ & $4.5 \times 10^{-2}$ & $2.3 \times 10^{-2}$ \\
\hline \multirow{6}{*}{ 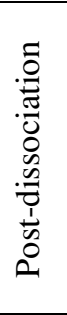 } & Compression index, $C_{c}[-]$ & 0.39 & 0.13 & 0.14 \\
\hline & Recompression index, $C_{r}[-]$ & 0.018 & 0.001 & 0.011 \\
\hline & Peak shear strength, $\tau[\mathrm{MPa}] @ \sigma^{\prime}=3 \mathrm{MPa}$ & & & 1.36 \\
\hline & Peak shear strength, $\tau[\mathrm{MPa}] @ \sigma^{\prime}=7.6 \mathrm{MPa}$ & & & 3.69 \\
\hline & Peak friction angle, $\varphi_{\text {peak }}\left[^{\circ}\right]$ & & & 27 \\
\hline & Residual friction angle, $\varphi_{\text {res }}\left[{ }^{\circ}\right]$ & & & 25 \\
\hline
\end{tabular}

Table 4. BIO measurements of depressurization rate and incubation temperature effects on the number of observed colony-forming units per gram of specimen collected (CFU/g).

\begin{tabular}{|c|c|c|c|c|c|c|c|c|c|c|}
\hline \multicolumn{2}{|c|}{ Temperature $\left[{ }^{\circ} \mathrm{C}\right]$} & \multicolumn{3}{|c|}{4} & \multicolumn{3}{|c|}{10} & \multicolumn{3}{|c|}{30} \\
\hline $\begin{array}{r}\text { Durati } \\
\text { depressu } \\
\text { from } 71 \\
0.11\end{array}$ & $\begin{array}{l}\mathrm{n} \text { of } \\
\text { zation } \\
\mathrm{Pa} \text { to } \\
\mathrm{Pa}\end{array}$ & $30 \mathrm{~min}$ & $1 \mathrm{~min}$ & $2 \mathrm{sec}$ & $30 \mathrm{~min}$ & $1 \mathrm{~min}$ & $2 \mathrm{sec}$ & $30 \mathrm{~min}$ & $1 \mathrm{~min}$ & $2 \mathrm{sec}$ \\
\hline $\begin{array}{l}\text { Colony- } \\
\text { time }\end{array}$ & $\begin{array}{l}\text { rming } \\
\text { ays] }\end{array}$ & N/A & 11 & 11 & 18 & 11 & 11 & 11 & 2 & 2 \\
\hline $\begin{array}{l}\text { Total cell } \\
\text { count }\end{array}$ & $\begin{array}{c}10^{-1} \\
\text { dilution }\end{array}$ & N/A & 2864 & 8901 & 3560 & 4687 & 11539 & 20174 & 4948 & 15372 \\
\hline$[\mathrm{CFU} / \mathrm{g}]$ & $\begin{array}{c}10^{-3} \\
\text { dilution }\end{array}$ & N/A & N/A & 24727 & N/A & 78125 & 45333 & N/A & 520834 & 32969 \\
\hline
\end{tabular}


Table 5. Constituent properties for small-strain wave velocity and stiffness analysis (Waite et al., 2009).

\begin{tabular}{lcc}
\hline \multicolumn{1}{c}{ Components } & $\begin{array}{c}\text { Density } \\
\left(\mathrm{kg} / \mathrm{m}^{3}\right)\end{array}$ & $\begin{array}{c}\text { Bulk Moduli } \\
(\mathrm{GPa})\end{array}$ \\
\hline Quartz & 2650 & 36.6 \\
Seawater & 1000 & 2.25 \\
Methane Hydrate & 925 & 8.41 \\
\hline
\end{tabular}

Table 6. Bulk small-strain stiffnesses and Poisson's ratio, calculated from Eqs. 7-10.

\begin{tabular}{cccccccccc}
\hline Core & $\begin{array}{c}\text { Location } \\
{[\mathrm{cm}]}\end{array}$ & $n[]$ & $S_{h}[]$ & $\begin{array}{c}\rho_{\text {mix }} \\
{\left[\mathrm{kg} / \mathrm{m}^{3}\right]}\end{array}$ & $\begin{array}{c}V p \\
{[\mathrm{~m} / \mathrm{s}]}\end{array}$ & $\begin{array}{c}\mathrm{Vs} \\
{[\mathrm{m} / \mathrm{s}]}\end{array}$ & $\begin{array}{c}B \\
{[\mathrm{GPa}]}\end{array}$ & $\begin{array}{c}M \\
{[\mathrm{GPa}]}\end{array}$ & $\begin{array}{c}G \\
{[\mathrm{GPa}]}\end{array}$ \\
\hline 8P, IPTC & 203.79 & 0.448 & 0.58 & 1838 & 2760 & 956 & 11.76 & 14.00 & 1.68 \\
& 190.20 & 0.448 & 0.49 & 1838 & 2302 & 861 & 7.92 & 9.74 & 1.36 \\
10P, DSC & $102-122$ & 0.461 & 0.15 & 1851 & 1900 & - & - & 6.68 & - \\
\hline
\end{tabular}

Table 7. Constituent properties for thermal property analysis.

\begin{tabular}{lllll}
\hline Property & Stainless steel, $s s^{\mathrm{a}}$ & Quartz, $q$ & Water, $w^{\mathrm{b}}$ & Hydrate, $h$ \\
\hline Latent heat, $L[\mathrm{~kJ} / \mathrm{kg}]$ & & & & $435^{\mathrm{c}}$ \\
Density, $\rho\left[\mathrm{kg} / \mathrm{m}^{3}\right]$ & 8000 & 2650 & 1000 & $929^{\mathrm{d}}$ \\
Specific heat, $c[\mathrm{~kJ} / \mathrm{kg} / \mathrm{K}]$ & 0.5 & 0.73 & 4.2 & $2.03^{\mathrm{d}}$ \\
Volume, $V\left[\mathrm{~m}^{3}\right]$ & 0.008592245 & 0.00016 & 0.001018 & 0.0000181 \\
\hline
\end{tabular}

${ }^{\mathrm{a}}$ ASM International (2002) $\quad{ }^{\mathrm{c}}$ Handa (1986)

${ }^{\mathrm{b}}$ Weast (1987) $\quad{ }^{\mathrm{d}}$ Waite et al. (2007) 


\section{Figure Captions}

Figure 1. Pressure Core Characterization Tools PCCTs, configured for 50.8-mm-diameter Nankai Trough cores. (A) Instrumented Pressure Testing Chamber IPTC; (B) Effective Stress Chamber ESC; (C) Direct Shear Chamber DSC; (D) Biological Sampling Cell BIO. Additional details are provided in Santamarina et al., (2012a; 2012b). Ball-valve closures are in deep red, flange clamps are in green, thermocouples are shown as thin red lines. Measurement sensors shown: compressional- and shear-wave velocity, $V_{P}$ and $V_{S}$, respectively; undrained shear strength $S_{u}$; electrical conductivity $\sigma_{e l}$; specimen length changes are measured with linear voltage displacement transducers LVDT.

Figure 2. Pressure Core Analysis and Transfer System PCATS X-ray core scans (Suzuki et al., 2015), aligned with Pressure Core Characterization Tool measurement locations and Instrumented Pressure Testing Chamber IPTC results. Shepard-classification soil descriptions are from Ito et al. (2015). (A) Core 8P was tested in the IPTC (orange arrows mark measurement locations), then subsampled for testing in the Biologic Chamber BIO, Direct Shear Cell DSC, and Effective Stress Cell ESC. IPTC results for compressional wave velocity $V_{P}$, shear wave velocity $V_{S}$, undrained shear strength $S_{u}$, and electrical conductivity $\sigma_{e l}$, are given in panels B-E. Solid circles represent locations with high hydrate saturation silty-sands, open circles represent locations with low hydrate saturation sediment, primarily clayey-silt. Solid lines represent expected baseline values for hydrate-free sediment. See Table 1 for IPTC results. (F) Core 10P was tested in the IPTC, then subsampled for testing in the DSC and ESC. IPTC results are given in panels G-J. (K) Core 20P was subsampled for testing in the DSC. 
Figure 3. IPTC cone penetrometer probe response difference between locations with high hydrate saturations (high $S_{h}$, blue solid circles), and low hydrate saturations (low $S_{h}$, green open circles). High $S_{h}$ locations tend to fracture during probe insertion, as indicated by the sudden post-peak softening ( 7.0-mm insertion when peak strength was recorded). In low- $S_{h}$ locations, the penetrometer reaches full insertion (17.6-mm insertion) and load relaxation occurs only when the probe is stationary.

Figure 4. Evolution of specimen void ratio during the complete loading history for ESC core 8P (A) and core 10P (B). Significant specimen shortening during dissociation in core 10P relative to that observed in core $8 \mathrm{P}$ is due to fines migration through gaps around the specimen's upper porous stone. The lower stone through which core $8 \mathrm{P}$ was vented has a sealed perimeter. Arrows indicate the experimental path in time.

Figure 5. Water permeability measurement in the ESC for core $8 \mathrm{P}$ before dissociation. (A) Measured differential pressure versus time during pore fluid extraction under constant flux, with effective pressure $\sigma_{v}{ }^{\prime}=3 \mathrm{MPa}$, pore pressure $u=10 \mathrm{MPa}$. $(\mathbf{B})$ The average differential pressure is determined using the slope of the integration of the measured differential pressure in $\mathbf{A}$ to cancel random noise. (C) Permeability is determined based on measurements under several different fluxes. The best fit of the $q$ versus $P / \mu$ slope gives the final permeability value.

Figure 6. Gas production test at an effective stress of $3 \mathrm{MPa}$ in the ESC. Pressure and temperature changes during dissociation of core $8 \mathrm{P}(\mathbf{A})$ and 10P $(\mathbf{B})$. The solid line is the phase boundary for methane hydrate in pure water and the dashed line is the phase boundary in 
seawater. Stability curves from Sloan and Koh (2007). Dissociation occurs along the freshwater stability curve, likely in response to dissociating hydrate being bathed in the freshwater generated as hydrate dissociates. Evolution along the freshwater stability curve is more noticeable in core $8 \mathrm{P}$, which is depressurized from its base so dissociating fluids flow over the ESC thermocouple. Core 10P is depressurized at the specimen top, so dissociating fluids flow away from the thermocouple, reducing the measurement sensitivity to temperature changes. Gas volume collected during the dissociation for core $8 \mathrm{P}(\mathbf{C})$ and 10P $(\mathbf{D})$. Dissociation occurs too rapidly to establish thermal or chemical equilibrium with the surrounding material or pore water, leading to temperatures depressed close to $0^{\circ} \mathrm{C}$ and fresh water concentrations large enough to control dissociation conditions.

Figure 7. Typical results from the DSC. (A) Relaxation test after first loading; (B) shear test: blue dots show peak shear before relaxation, green dots show shear strength after shear relaxation. Dotted box indicates the initial "seating effect" as the specimen responds to the axial load contacting the non-parallel top and bottom faces of the specimen.

Figure 8. Mobilized friction angle, $\varphi$, measured in the DSC before (A) and after $(\mathbf{B})$ hydrate dissociation in Core 20P. Blue squares and green circles, respectively, represent measurements made before and after the specimen relaxes after each displacement (see Fig. 7B). Hydrate significantly alters the friction angle when measured immediately after a displacement (blue squares), but values measured after the system relaxes (green circles) are controlled primarily by mineralogy. The specimen contains 12-15 wt\% smectite (Egawa et al., 2015). For reference, 
crosses are plotted for measurements on dry mixtures of quartz sand and $20 \mathrm{wt} \%$ smectite (Mollins et al., 1999).

Figure 9. P-waveforms measured in the DSC for Core 10 while depressurizing the cell to cause dissociation. Depressurization progresses from top to bottom in the figure. Waveforms are normalized by their specimen lengths to cancel the effects of specimen shortening during dissociation. Black curves are measured while the specimen is within the hydrate stability conditions, red curves are measured after $u_{\text {cell }}$ is reduced below the hydrate stability pressure at $6^{\circ} \mathrm{C}$. Amplitude loss for pressures below the hydrate stability pressure (red curves) is in agreement with empirical results for the addition of gas to an otherwise water-saturated porous material (Murphy, 1982; Santamarina et al., 2001).

Figure 10. Sampling of the biological diversity in core $8 \mathrm{P}$ using the BIO chamber. Images are taken after culturing for 32 days at atmospheric pressure, under oxic conditions. Top row cultured at $4^{\circ} \mathrm{C}$, bottom row cultured at $30^{\circ} \mathrm{C}$. Depressurization rates and dilutions vary: (A) $7 \mathrm{MPa} / 2 \mathrm{sec}, 10^{-3}$ dilution; (B) $7 \mathrm{MPa} / 2 \mathrm{sec}, 10^{-1}$ dilution; (C) $7 \mathrm{MPa} / 1 \mathrm{~min}, 10^{-3}$ dilution; (D) $7 \mathrm{MPa} / 30 \mathrm{~min}, 10^{-1}$ dilution. Variety in colony color and edge morphology likely indicate the presence of several microbial species. Microbial identification is not part of the BIO chamber's specimen acquisition "proof-of-concept" test.

Figure 11. (A) Compressional $V_{P}$ and (B) Shear $V_{S}$ wave velocity in hydrate-bearing sands. Under gas-limited conditions in marine sands, hydrate nucleates and initially grows into the pore space (i.e. "pore filling"), to eventually become "load bearing" as the hydrate volume in the pore increases (Dvorkin et al., 2000; Yun et al., 2005). IPTC measurements in a high $S_{h}$ section of 
core $8 \mathrm{P}$ (filled circles), and DSC measurement in a low $S_{h}$ section of core 10P (filled diamond in A) can all be fitted by the model that assumes hydrate is homogeneously distributed as a loadbearing component of the sediment (Dvorkin et al., 2000). Schematics show grey, circular sand grains and black hydrate mass. Cementation curves are also calculated from Dvorkin et al. (2000), and curves for sand with spherical hydrate patches are calculated from Berryman (1995). Theoretical curve color scheme is the same in A and B.are best fit by assuming hydrate is homogeneously distributed as a load-bearing component of the sediment. Schematics show grey, circular sand grains and black hydrate mass. Curves for sand with spherical hydrate patches are calculated from, remaining curves are calculated from. Theoretical curve color scheme is the same in $\mathbf{A}$ and $\mathbf{B}$.

Figure 12. Dependence of compressional wave velocity $V_{P}$ on effective stress in the DSC specimen from core 10P. Pressure cores are collected and stored with no effective stress. The PCATS measurement of $V_{P}$ (red star, Suzuki et al., 2015) one week after collecting core 10P shows evidence of $V_{P}$ reduction from in situ values that is more significant that the reduction expected from rapid removal of the effective stress (filled black squares, measured in DSC). The core expansion, or aging observed by Nagano et al. (2015), is likely responsible for the remaining drop in $V_{P}$ apparent in the PCATS measurement. Additional expansion and unloading at sediment grain contacts occurs during the subsequent 27 weeks of storage at zero effective stress, but within the hydrate stability conditions, causing an additional $5 \%$ drop in $V_{P}$ (IPTC measurement, co-located with PCATS measurement, red circle). DSC reapplication of a vertical effective stress to the specimen reverses the unloading and aging effects on $V_{P}$ (filled black 
circles). The break in slope near $2.8 \mathrm{MPa}$ applied stress is in good agreement with the in situ vertical effective stress, estimated to be $2.32 \mathrm{MPa}$.

Figure 13. Measured permeability in hydrate-bearing sediment relative to the permeability in hydrate-free sediment (filled circle at $S_{h}=0.18$ for core $8 \mathrm{P}$, and 0.74 for core $10 \mathrm{P}$ ). Theoretical trends are shown for several possible hydrate morphologies (schematics have sediment shown in grey, hydrate in black). Results suggest hydrate is primarily forming as a non-cementing pore-fill (model in Kleinberg et al., (2003)), as can be expected if hydrate initially forms in the largest pores through which pore fluid advection is strongest. If hydrate is assumed to be distributed in patches throughout the sediment, the relative permeability is overpredicted in the spherical-grain case (Berryman, 1995), but is in agreement with a modified Kozeny-Carman approach in which the pore space is assumed to be a network of water-filled capillaries (white segments) with hydrate forming a patchy filling of the larger-diameter capillaries (black segments, model in Dai and Seol, (2014)).

Figure 14. Permeability measurements for core $8 \mathrm{P}$ in the ESC after hydrate dissociation (blue circles), while the specimen pore space contains gas and the water saturation $S_{w}<1$. Permeability measurements are made at different pore pressure levels as the specimen is repressurized with water to $u_{\text {cell }}=10 \mathrm{MPa}$ at $18^{\circ} \mathrm{C}$ to resaturate the specimen without reforming hydrate. The measured residual water saturation after depressurization for this specimen is $S_{r w}=$ 0.16. Relative permeability $k_{r w}$ dependence on $S_{w}$ during repressurization can be estimated (solid curve) with the Brooks and Corey (1964) model, where the best fit curve is nearly identical to the prediction using the parameters from Kurihara et al., (2011). 
Figure 15. Dependence of cell count on depth from the ground surface. Cells can only occupy pores larger than the cell size; the probability of finding pores of viable host size decreases with depth due to compaction, and with grain specific surface $S_{S}$ due to the presence of fine particles in the pore space (Phadnis and Santamarina, 2011). Nankai Trough data from other studies are included (Kormas et al., 2003; Li et al., 1999; Mills et al., 2012; Newberry et al., 2004; Reed et al., 2002). The shaded region represents results from other locations compiled in Parkes et al. (1994; 2009). Cell counts in this study were taken from a BIO specimen with $S_{S}=19.4 \mathrm{~m} 2 / \mathrm{g}$, but the cell counts include only live, culturable aerobes, so a reduced cell count is expected relative to theoretical estimates (dashed curves) and compiled data (symbols and shaded region), which all include living and dead organisms. Compiled data points are obtained based either on cell weight $(\mathrm{x})$ or a staining method (solid diamonds). 


\section{References}

Archie, G.E., 1942. The electrical resistivity log as an aid in determining some reservoir characteristics. Transactions of The American Institute of Mining, Metallurgical, and Petroleum Engineers 146, 5462.

ASM International Materials Properties Database Committee, 2002. ASM Ready Reference: Thermal Properties of Metals, F. Cverna (ed.). ASM International, Materials Park, OH.

Beringen, F.L., Kolk, H.J., Windle, D., 1982. Cone penetration and laboratory testing in marine calcareous sediments, in: Demars, K.R., Chaney, R.C. (Eds.), Geotechnical Properties, Behavior, and Performance of Calcareous Soils. American Society for Testing and Materials, pp. 179-209.

Berryman, J.G., 1995. Mixture theories for rock properties, in: Ahrens, T.J. (Ed.), A Handbook of Physical Constants. American Geophysical Union, Washington, D.C., pp. 205-228.

Brooks, R.H., Corey, A.T., 1964. Hydraulic properties of porous media. Colorado State University, Hydrology Papers, 24 pp.

Choi, J.-H., Dai, S., Cha, J.-H., Seol, Y., 2014. Laboratory formation of noncementing hydrates in sandy sediments. Geochemistry Geophysics Geosystems 15, doi:10.1002/ 2014GC005287, 1648-1656.

Conin, M., Henry, P., Bourlange, S., Raimbourg, H., Reuschlé, T., 2011. Interpretation of porosity and LWD resistivity from the Nankai accretionary wedge in light of clay physicochemical properties: Evidence for erosion and local overpressuring. Geochemistry, Geophysics, Geosystems, 12(3), Q0AD07, doi:10.1029/2010GC003381, 17 p.

Dai, S., Santamarina, J.C., 2014. Sampling disturbance in hydrate-bearing sediment pressure cores: NGHP-01 expedition, Krishna-Godavari Basin example. Marine and Petroleum Geology 58, doi: 10.1016/j.marpetgeo.2014.07.013, 178-186.

Dai, S., Seol, Y., 2014. Water permeability in hydrate-bearing sediments: A pore-scale study. Geophysical Research Letters 41(12), doi:10.1002/2014GL060535, 4176-4184.

Dvorkin, J., Helgerud, M.B., Waite, W.F., Kirby, S.H., Nur, A., 2000. Introduction to physical properties and elasticity models, in: Max, M.D. (Ed.), Natural Gas Hydrate In Oceanic and Permafrost Environments. Kluwer Academic Publishers, Dordrecht, Netherlands, pp. 245-260.

Egawa, K., Nishimura, O., Izumi, S., Fukami, E., Jin, Y., Kida, M., Konno, Y., Yoneda, J., Ito T, Suzuki, K., Nakatsuka, Y. and Nagao, J. 2015. Bulk sediment mineralogy of gas hydrate reservoir at the East Nankai offshore production test site, Marine and Petroleum Geology, in this issue.

Fohrmann, M., Pecher, I.A., 2012. Analysing sand-dominated channel systems for potential gas-hydratereservoirs using an AVO seismic inversion technique on the Southern Hikurangi Margin, New Zealand. Marine and Petroleum Geology 38, 19-34.

Fujii, T., Noguchi, S., Takayama, T., Suzuki, K., Yamamoto, K., Saeki, T., 2013. Site selection and formation evaluation at the 1st offshore methane hydrate production test site in the Eastern Nankai Trough, Japan, 75th EAGE Conference, London, UK, paper B10.

Fujii, T., Saeki, T., Kobayashi, T., Inamori, T., Hayashi, M., Takano, O., Takayama, T., Kawasaki, T., Nagakubo, S., Nakamizu, M., Yokoi, K., 2008. Resource assessment of methane hydrate in the eastern Nankai Trough, Japan, in: Englezos, P., Ripmeeser, J. (Eds.), Proceedings of the 6th International Conference on Gas Hydrates, Vancouver, Canada, Paper 5673, 12 p.

Fujii, T., Suzuki, K., Takayama, T., Tamaki, M., Komatsu, Y., Konno, Y., Yoneda, J., Yamamoto, K. and Nagao, J. (2015): Geological settings and characterization of methane hydrate reservoir distributed on the Daini-Atsumi knoll in the Eastern Nankai Trough, Japan., Marine and Petroleum Geology, in this issue.

Handa, Y.P., 1986. Compositions, enthalpies of dissociation, and heat capacities in the range 85 to $270 \mathrm{~K}$ for clathrate hydrates of methane, ethane, and propane, and enthalpy of dissociation of isobutane hydrate, as determined by a heat-flow calorimeter. Journal of Chemical Thermodynamics 18, 915-921. 
Helgerud, M.B., Waite, W.F., Kirby, S.H., Nur, A., 2009. Elastic wave speeds and moduli in polycrystalline ice Ih, sI methane hydrate, and sII methane-ethane hydrate. Journal of Geophysical Research 114, B02212, doi:10.1029/2008JB006132, 11p.

Hunter, R.B., Collett, T.S., Boswell, R., Anderson, B.J., Digert, S.A., Pospisil, G., Baker, R., Weeks, M., 2011. Mount Elbert Gas Hydrate Stratigraphic Test Well, Alaska North Slope: Overview of scientific and technical program. Marine and Petroleum Geology 28, 295-310.

Inada, N. and Yamamoto, K., 2015: Data Report: Pressure coring and shipboard core handling in the Nankai Project, Marine and Petroleum Geology, in this issue.

Ito, T., Komatsu, Y., Fujii, T., Suzuki, K., Egawa, K., Nakatsuka, Y., Konno, Y., Yoneda, J., Jin, Y., Kida, M., Nagao, J. and Minagawa, H., 2015: Lithological features of hydrate-bearing sediments and their relationship with gas hydrate saturation in the eastern Nankai Trough, Japan, Marine and Petroleum Geology, in this issue.

Jang, J., Santamarina, J.C., 2011. Recoverable gas from hydrate-bearing sediments: Pore network model simulation and macroscale analyses. Journal of Geophysical Research: Solid Earth (1978-2012) 116.

Jung, J.-W., Santamarina, J.C., Soga, K., 2012a. Stress-strain response of hydrate-bearing sands: Numerical study using discrete element method simulations. Journal of Geophysical Research 117, doi:10.1029/2011jb009040, 12 p.

Jung, J.W., Jang, J., Santamarina, J.C., Tsouris, C., Phelps, T.J., Rawn, C.J., 2012b. Gas Production from Hydrate-Bearing Sediments: The Role of Fine Particles. Energy \& Fuels 26, 480-487.

Kida, M., Jin, Y., Watanabe, M., Konno Y., Yoneda, J., Egawa, K., Ito, T., Nakatsuka, Y., Suzuki, K., Fujii, T. and Nagao, J., 2015: Chemical and crystallographic characterizations of natural gas hydrates recovered from a production test site in the Eastern Nankai Trough, Marine and Petroleum Geology, in this issue.

Kleinberg, R.L., Flaum, C., Griffin, D.D., Brewer, P.G., Malby, G.E., Peltzer, E.T., Yesinowski, J.P., 2003. Deep sea NMR: Methane hydrate growth habit in porous media and its relationship to hydraulic permeability, deposit accumulation, and submarine slope stability. Journal of Geophysical Research 108(B10), 2508, doi:10.1029/2003JB002389, 17p.

Konno, Y., Yoneda, J., Egawa, K., Ito., T., Jin, Y., Kida, M., Suzuki, K., Fujii, T. and Nagao, J., 2015: Permeability of sediment cores from methane hydrate deposit in the Eastern Nankai Trough, Marine and Petroleum Geology, in this issue.

Kormas, K.A., Smith, D.C., Edgcomb, V., Teske, A., 2003. Molecular analysis of deep subsurface microbial communities in Nankai Trough sediments (ODP Leg 190, Site 1176). Fems Microbiology Ecology 45, 115-125.

Kurihara, M., Sato, A., Funatsu, K., Ouchi, H., Masuda, Y., Narita, H., Collett, T.S., 2011. Analysis of formation pressure test results in the Mount Elbert methane hydrate reservoir through numerical simulation. Marine and Petroleum Geology 28, 502-516.

Lee, J.Y., Francisca, F.M., Santamarina, J.C., Ruppel, C., 2010a. Parametric study of the physical properties of hydrate-bearing sand, silt, and clay sediments: 2. Small-strain mechanical properties. Journal of Geophysical Research 115(B11), B11105, doi: 10.1029/2009jb006670, 11p.

Lee, J.Y., Jung, J.W., Lee, M.H., Bahk, J.J., Choi, J., Ryu, B.J., Schultheiss, P., 2013. Pressure core based study of gas hydrates in the Ulleung Basin and implication for geomechanical controls on gas hydrate occurrence. Marine and Petroleum Geology 47, 85-98.

Lee, J.Y., Santamarina, J.C., Ruppel, C., 2010b. Parametric study of the physical properties of hydratebearing sand, silt, and clay sediments: 1. Electromagnetic properties. Journal of Geophysical Research 115(B11), B11104, doi:10.1029/2009JB006669, 9 p.

Li, L., Guenzennec, J., Nichols, P., Henry, P., Yanagibayashi, M., Kato, C., 1999. Microbial diversity in Nankai Trough sediments at a depth of 3,843 m. Journal of Oceanography 55, 635-642.

Lu, W., Chou, I.M., Burruss, R.C., 2008. Determination of methane concentrations in water in equilibrium with sI methane hydrate in the absence of a vapor phase by in situ Raman spectroscopy. Geochimica et Cosmochimica Acta 72, 412-422. 
Madigan, M.T., Martinko, J.M., Dunlap, P.V., Clark, D.P., 2009. Brock Biology of Microorganisms, 12th ed. Pearson Education, Inc.

Matsumoto, R., Tomaru, H., Lu, H., 2004. Detection and Evaluation of Gas Hydrates in the Eastern Nankai Trough by Geochemical and Geophysical Methods. Resource Geology 54, 53-67.

Mavko, G., Mukerji, T., Dvorkin, J., 1998. The rock physics handbook: Tools for seismic analysis in porous media. Cambridge University Press, Cambridge.

Mesri, G., 1989. A Reevaluation of $\mathrm{Su}=0.22$-Sigma'p Using Laboratory Shear Tests. Canadian Geotechnical Journal 26, 162-164.

Mills, H.J., Reese, B.K., Shepard, A.K., Riedinger, N., Dowd, S.E., Morono, Y., Inagaki, F., 2012. Characterization of metabolically active bacterial populations in subseafloor Nankai Trough sediments above, within, and below the sulfate-methane transition zone. Frontiers in Microbiology 3, doi: 10.3389/fmicb.2012.00113, 12p.

Mollins, L.H., Stewart, D.I., Cousens, T.W., 1999. Drained strength of bentonite-enhanced sand. Geotechnique 49, 523-528.

Murphy, W.F., 1982. Effects of Partial Water Saturation on Attenuation in Massilon Sandstone and Vycor Porous-Glass. Journal of the Acoustical Society of America 71, 1458-1468.

Nagano, Y., Lin, W. and Yamamoto, K., 2015: In-situ stress analysis using the anelastic strain recovery (ASR) method at the first offshore gas production test site in the eastern Nankai Trough, Japan, Marine and Petroleum Geology, in this issue.

Newberry, C.J., Webster, G., Cragg, B.A., Parkes, R.J., Weightman, A.J., Fry, J.C., 2004. Diversity of prokaryotes and methanogenesis in deep subsurface sediments from the Nankai Trough, Ocean Drilling Program Leg 190. Environmental Microbiology 6, 274-287.

Parkes, R.J., Cragg, B.A., Bale, S.J., Getliff, J.M., Goodman, K., Rochelle, P.A., Fry, J.C., Weightman, A.J., Harvey, S.M., 1994. Deep Bacterial Biosphere in Pacific-Ocean Sediments. Nature 371, 410-413.

Parkes, R.J., Sellek, G., Webster, G., Martin, D., Anders, E., Weightman, A.J., Sass, H., 2009. Culturable prokaryotic diversity of deep, gas hydrate sediments: first use of a continuous high-pressure, anaerobic, enrichment and isolation system for subseafloor sediments (DeepIsoBUG). Environmental Microbiology 11, 3140-3153.

Pearson, D.F., Halleck, P.M., McGuire, P.L., Hermes, R., Matthews, M., 1983. Natural Gas Hydrate Deposits: A Review of In Situ Properties. Journal of Physical Chemistry 87(21), 4180-4185.

Phadnis, H.S., Santamarina, J.C., 2011. Bacteria in sediments: pore size effects. Geotechnique Letters 1, doi: 10.1680/geolett.11.00008, 91-93.

Priest, J.A., Rees, E.V.L., Clayton, C.R.I., 2009. Influence of gas hydrate morphology on the seismic velocities of sands. Journal of Geophysical Research 114(B11), B11205, doi: 10.1029/2009jb006284, $13 \mathrm{p}$.

Priest, J. A., Druce, M., Roberts, J., Schultheiss, P., Nakatsuka, Y. and Suzuki, K. (2014): Shipboard triaxial strength measurements of hydrate-bearing pressure core from the Nankai Trough, Marine and Petroleum Geology, in this issue.

Reagan, M.T., Moridis, G.J., 2008. Dynamic response of oceanic hydrate deposits to ocean temperature change. Journal of Geophysical Research 113, C12023, doi:10.1029/2008JC004938, 21p.

Reed, D.W., Fujita, Y., Delwiche, M.E., Blackwelder, D.B., Sheridan, P.P., Uchida, T., Colwell, F.S., 2002. Microbial communities from methane hydrate-bearing deep marine sediments in a forearc basin. Applied and Environmental Microbiology 68, 3759-3770.

Reuschle, T., 2011. Data report: permeability measurements under confining pressure, Expeditions 315 and 316, Nankai Trough, in: Kinoshita, M., Tobin, H., Ashi, J., Kimura, G., Lallemant, S., Screaton, E.J., Curewitz, D., Masago, H., Moe, K.T., Expedition 314/315/316 Scientists (Eds.), Proceedings of the Integrated Ocean Drilling Program. IODP, Washington D.C., doi:10.2204/iodp.proc.314315316.205.2011, 17p.

Rutqvist, J., Moridis, G.J., 2007. Numerical Studies of Geomechanical Stability of Hydrate-Bearing Sediments, Offshore Technology Conference, paper OTC 18860, Houston, Texas, U.S.A, p. 21 p. 
Santamarina, J.C., Dai, S., Jang, J., Terzariol, M., 2012a. Pressure core characterization tools for hydratebearing sediments. Scientific Drilling 14, 44-48.

Santamarina, J.C., Klein, K.A., Fam, M.A., 2001. Soils and Waves: Particulate materials behavior, chracterization and process monitoring. John Wiley \& Sons, Ltd., New York.

Santamarina, J.C., Ruppel, C., 2008. The impact of hydrate saturation on the mechanical, electrical, and thermal properties of hydrate-bearing sand, silts, and clay, in: Englezos, P., Ripmeeser, J. (Eds.), Proceedings of the 6th International Conference on Gas Hydrates, Vancouver, Canada, pp. Paper $5817,5812 \mathrm{p}$.

Santamarina, J.C., Ruppel, C., 2010. The impact of hydrate saturation on the mechanical, electrical, and thermal properties of hydrate-bearing sand, silts, and clay, in: Riedel, M., Willoughby, E.C., Chopra, S. (Eds.), Geophysical Characterization of Gas Hydrates. Society of Exploration Geophysicists Geophysical Developments, pp. 373-384.

Santamarina, J.C., Winters, W.J., Dai, S., Jang, J., Terzariol, M., Papadopoulos, E., Mason, D., Waite, W., Bergeron, E., 2012b. Pressure core characterization tools to enhance gas hydrate field programs. Fire in the Ice: Department of Energy, Office of Fossil Energy, National Energy Technology Laboratory, Methane Hydrate News Letter 12, 7-9.

Shankar, U., Riedel, M., 2014. Assessment of gas hydrate saturation in marine sediments from resistivity and compressional-wave velocity log measurements in the Mahanadi Basin, India. Marine and Petroleum Geology 58, 265-277.

Shelander, D., Dai, J.C., Bunge, G., Singh, S., Eissa, M., Fisher, K., 2012. Estimating saturation of gas hydrates using conventional 3D seismic data, Gulf of Mexico Joint Industry Project Leg II. Marine and Petroleum Geology 34, 96-110.

Sloan, E.D., Koh, C.A., 2007. Clathrate Hydrates of Natural Gases, Third Edition. CRC Press, Boca Raton.

Spangenberg, E., 2001. Modeling of the influence of gas hydrate content on the electrical properties of porous sediments. Journal of Geophysical Research 106, 6535-6548.

Spangenberg, E., Kulenkampff, J., 2006. Influence of methane hydrate content on electrical sediment properties. Geophysical Research Letters 33, L24315, doi:10.1029/2006GL028188, 5p.

Stryjek, R., Vera, J.H., 1986. Prsv - an Improved Peng-Robinson Equation of State for Pure Compounds and Mixtures. Canadian Journal of Chemical Engineering 64, 323-333.

Suzuki, K., Schultheiss, P., Ito, T., Nakatsuka, Y., Egawa, K. and Yamamoto, K., 2015: Overview: Physical properties and sedimentological features of hydrate-bearing samples recovered from the first gas production test site on Daini-Atsumi knoll around Eastern Nankai Trough, Marine and Petroleum Geology, in this issue.

Takahashi, H., Tsuji, Y., 2005. Multi-well exploration program in 2004 for natural hydrate in the NankaiTrough offshore Japan. Offshore Technology Conference, Houston, TX. May 2-5, 2005, paper OTC 17162, 10p.

Terzaghi, K., Peck, R.B., Mesri, G., 1996. Soil mechanics in engineering practice, 3rd ed. John Wiley and Sons, New York.

Tsuji, Y., Ishida, H., Nakamizu, M., Matsumoto, R., Shimizu, S., 2004. Overview of the MITI Nankai Trough Wells: A Milestone in the Evaluation of Methane Hydrate Resources. Resource Geology 54, 3-10.

Uchida, T., Lu, H., Tomaru, H., 2004. Subsurface Occurrence of Natural Gas Hydrate in the Nankai Trough Area: Implication for Gas Hydrate Concentration. Resource Geology 54, 35-44.

Uchida, T., Waseda, A., Namikawa, T., 2009. Methane accumulation and high concentration of gas hydrate in marine and terrestrial sandy sediments, in: Collett, T., Johnson, A., Knapp, C., Boswell, R. (Eds.), Natural Gas Hydrates - Energy Resource and Associated Geologic Hazards. AAPG/NETL/AAPG Foundation/AAPG EMD, AAPG Memoir 89, pp. 401-413.

Valdes, J.R., Santamarina, J.C., 2007. Particle transport in a nonuniform flow field: Retardation and clogging. Applied Physics Letters 90, 244101, doi:10.1063.1.2748850, 3p. 
Waite, W.F., Kneafsey, T.J., Winters, W.J., Mason, D.H., 2008. Physical property changes in hydratebearing sediment due to depressurization and subsequent repressurization. Journal of Geophysical Research 113, B07102, doi:10.1029/2007JB005351, 12p.

Waite, W.F., Santamarina, J.C., Cortes, D.D., Dugan, B., Espinoza, D.N., Germaine, J., Jang, J., Jung, J.W., Kneafsey, T.J., Shin, H., Soga, K., Winters, W.J., Yun, T.S., 2009. Physical properties of hydrate-bearing sediments. Reviews of Geophysics 47, RG4003, doi:10.1029/2008RG000279, 38p.

Waite, W.F., Stern, L.A., Kirby, S.H., Winters, W.J., Mason, D.H., 2007. Simultaneous determination of thermal conductivity, thermal diffusivity and specific heat in sI methane hydrate. Geophysical Journal International 169, doi: 10.1111/j.1365-246X.2007.03382.x, 767-774.

Waseda, A., Uchida, T., 2004a. The Geochemical Context of Gas Hydrate in the Eastern Nankai Trough. Resource Geology 54, 69-78.

Waseda, A., Uchida, T., 2004b. Origin and migration of methane in gas hydrate-bearing sediments in the Nankai Trough, in: Ronald J. Hill, J.L.Z.A.M.J.B.G.C.R.E.M.G., Kenneth, P. (Eds.), The Geochemical Society Special Publications. Elsevier, pp. 377-387.

Weast, R.C., 1987. CRC Handbook of Chemistry and Physics, 68 ed. CRC Press, Inc., Boca Raton.

Yamamoto, K., 2013. Japan completes first offshore methane hydrate production test - methane successfully produced from deepwater hydrate layers. Fire in the Ice: Department of Energy, Office of Fossil Energy, National Energy Technology Laboratory, Methane Hydrate News Letter 13, 1-2.

Yamamoto, K., Inada, N., Kubo, S., Fujii, T., Suzuki, K., Konno, Y., Shipboard Scientists for the Methane Hydrate Offshore Production Test, 2012. Pressure core sampling in the Eastern Nankai Trough. Fire in the Ice: Department of Energy, Office of Fossil Energy, National Energy Technology Laboratory, Methane Hydrate News Letter 12, 1-6.

Yamamoto, K., 2015, Overview and introduction: pressure core-sampling and analyses in the 2012-2013 MH21 offshore test of gas production from methane hydrates in the eastern Nankai Trough, Marine and Petroleum Geology, in this issue.

Yoneda, J., Masui, A., Konno, Y., Jin, Y., Egawa, K., Kida, M., Ito, T., Nagao, J. and Tenma, N., 2015: Mechanical properties of hydrate-bearing turbidite reservoir in the first gas production test site of the Eastern Nankai Trough, Marine and Petroleum Geology, in this issue.

Yun, T.S., Francisca, F.M., Santamarina, J.C., Ruppel, C., 2005. Compressional and shear wave velocities in uncemented sediment containing gas hydrate. Geophysical Research Letters 32, L10609, doi:10610.11029/12005GL022607.

Yun, T.S., Lee, C., Lee, J.-S., Bahk, J.J., Santamarina, J.C., 2011. A pressure core based characterization of hydrate-bearing sediments in the Ulleung Basin, Sea of Japan (East Sea). Journal of Geophysical Research 116, B02204, doi:10.1029/2010JB007468, 12p.

Yun, T.S., Narsilio, G.A., Santamarina, J.C., Ruppel, C., 2006. Instrumented pressure testing chamber for characterizing sediment cores recovered at in situ hydrostatic pressure. Marine Geology 229, 285-293. 
A

$\longrightarrow$ Manipulator $\quad$ IPTC

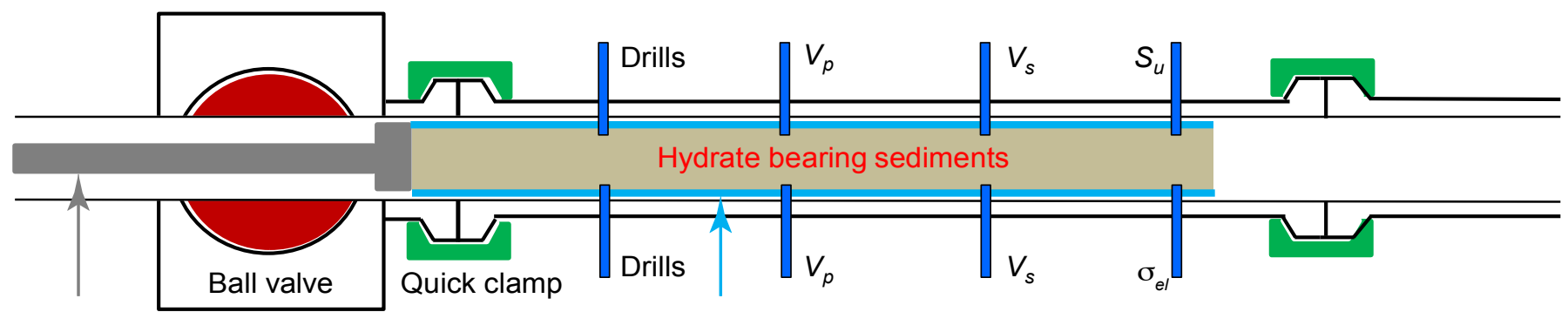

Manipulator control arm

Plastic core liner
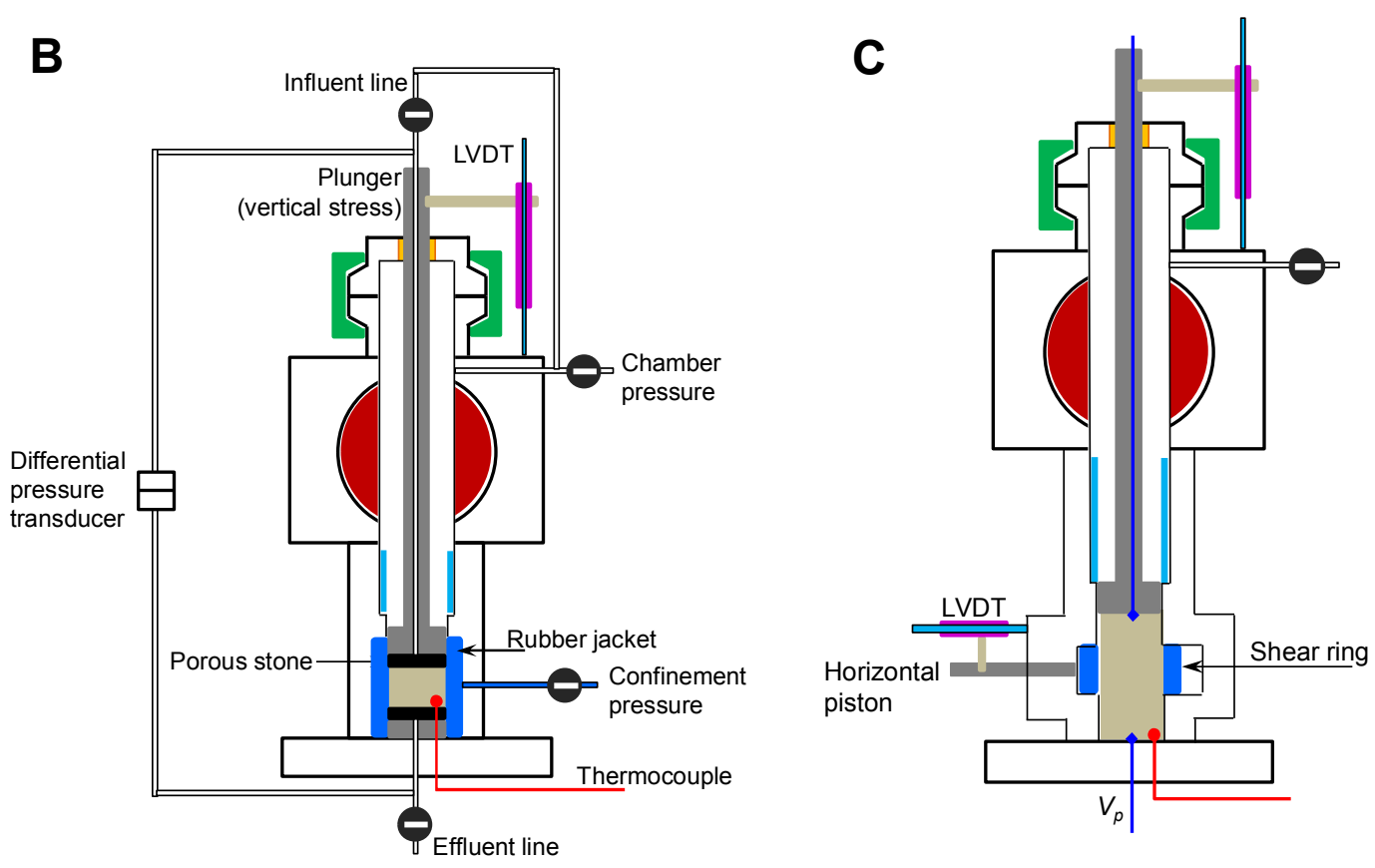

D

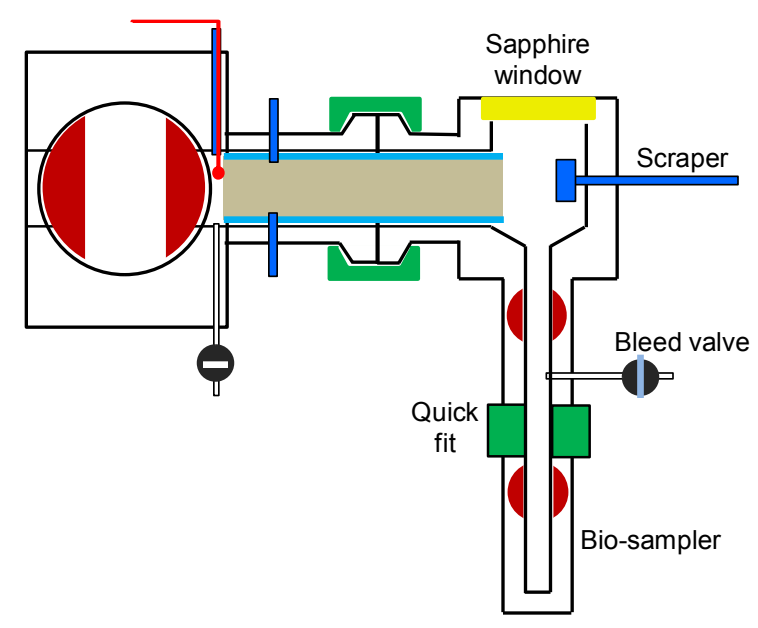

Figure 1. Pressure Core Characterization Tools PCCTs, configured for 50.8-mm-diameter Nankai Trough cores. (A) Instrumented Pressure Testing Chamber IPTC; (B) Effective Stress Chamber ESC; (C) Direct Shear Chamber DSC; (D) Biological Sampling Cell BIO. Additional details are provided in Santamarina et al. (2012a,b). Ball-valve closures are in deep red, flange clamps are in green, thermocouples are shown as thin red lines. Measurement sensors shown: compressional- and shear-wave velocity, $V_{P}$ and $V_{S}$, respectively; undrained shear strength $S_{u}$; electrical conductivity $\sigma_{e l}$; specimen length changes are measured with linear voltage displacement transducers LVDT. 


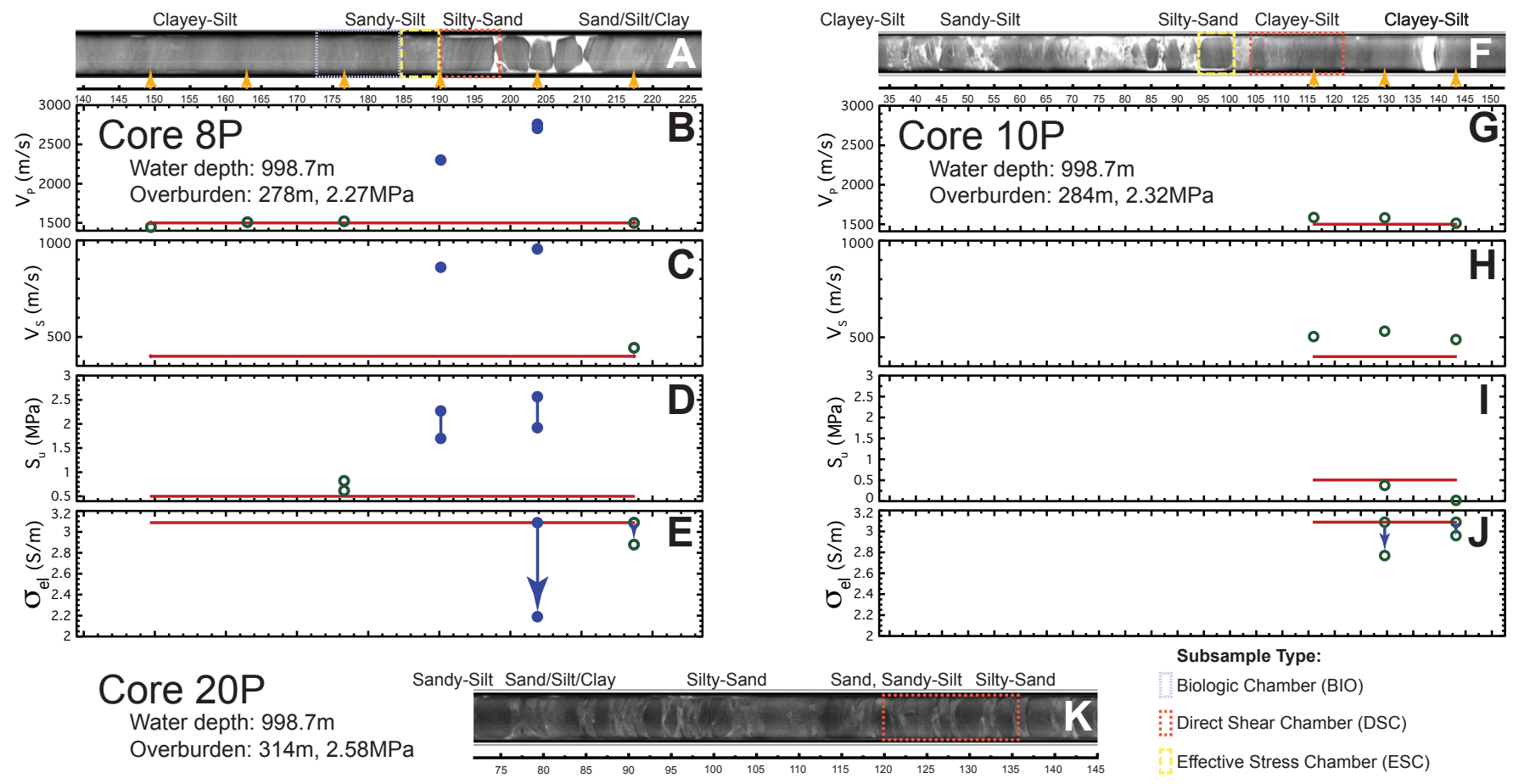

Figure 2. Pressure Core Analysis and Transfer System PCATS X-ray core scans (Suzuki et al., this volume), aligned with Pressure Core Characterization Tool measurement locations and Instrumented Pressure Testing Chamber IPTC results. Shepard-classification soil descriptions are from Ito et al. (this volume). (A) Core $8 \mathrm{P}$ was tested in the IPTC (orange arrows mark measurement locations), then subsampled for testing in the Biologic Chamber BIO, Direct Shear Cell DSC, and Effective Stress Cell ESC. IPTC results for compressional wave velocity $V_{P}$, shear wave velocity $V_{S}$, undrained shear strength $S_{u}$, and electrical conductivity $\sigma_{e l}$, are given in panels B-E. Solid circles represent locations with high hydrate saturation silty-sands, open circles represent locations with low hydrate saturation sediment, primarily clayey-silt. Solid lines represent expected baseline values for hydrate-free sediment. See Table 1 for IPTC results. (F) Core 10P was tested in the IPTC, then subsampled for testing in the DSC and ESC. IPTC results are given in panels G-J. (K) Core 20P was subsampled for testing in the DSC. 


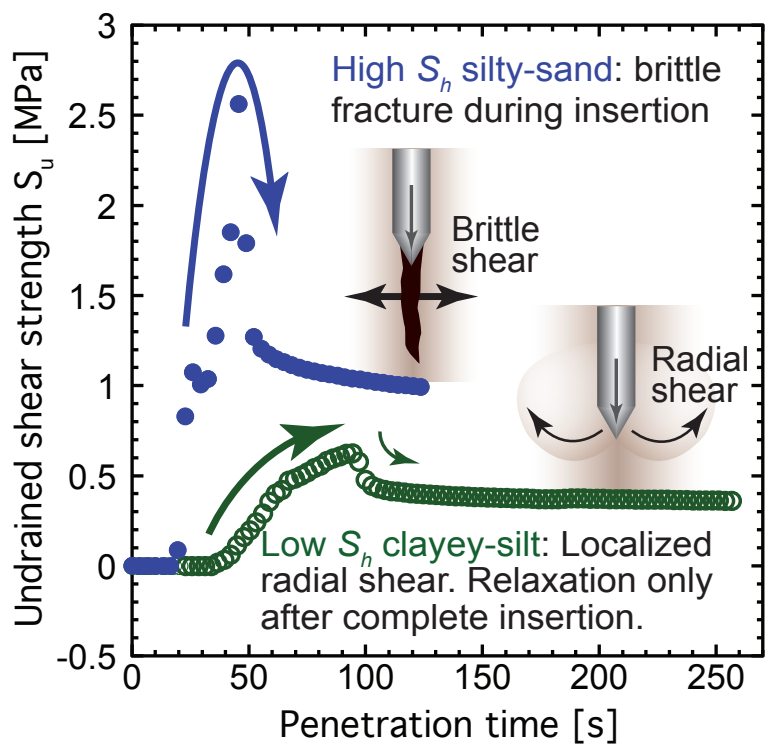

Figure 3. IPTC cone penetrometer probe response difference between locations with high hydrate saturations (high $S_{h}$, blue solid circles), and low hydrate saturations (low $S_{h}$, green open circles). High- $S_{h}$ locations tend to fracture during probe insertion, as indicated by the sudden post-peak softening ( 7.0-mm insertion when peak strength was recorded). In low $-S_{h}$ locations, the penetrometer reaches full insertion (17.6$\mathrm{mm}$ insertion) and load relaxation occurs only when the probe is stationary. 

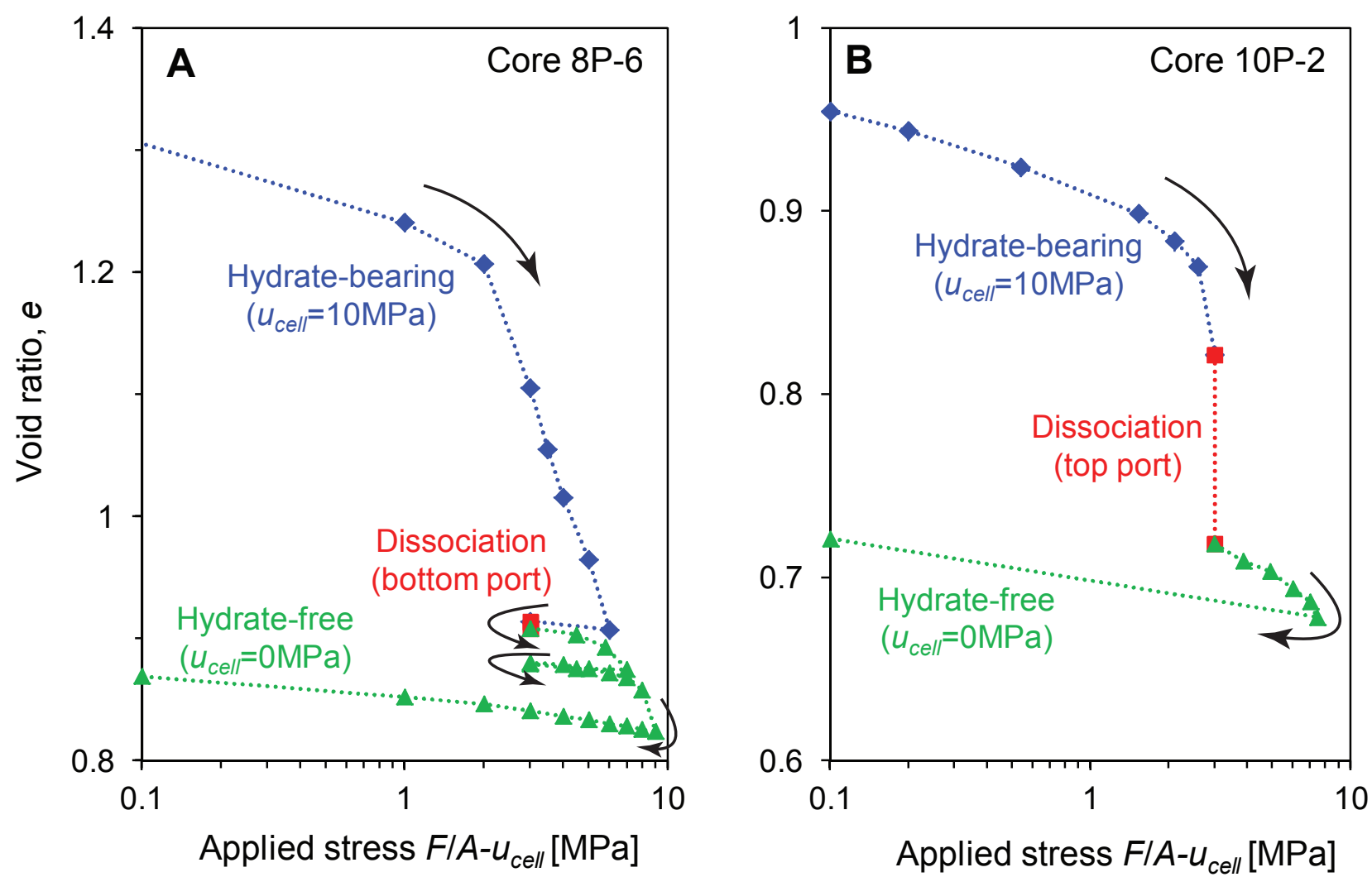

Figure 4. Evolution of specimen void ratio during the complete loading history for ESC core 8P (A) and core 10P $(\mathbf{B})$. Significant specimen shortening during dissociation in core 10P relative to that observed in core 8P is due to fines migration through gaps around the specimen's upper porous stone. The lower stone through which core $8 \mathrm{P}$ was vented has a sealed perimeter. Arrows indicate the experimental path in time. 

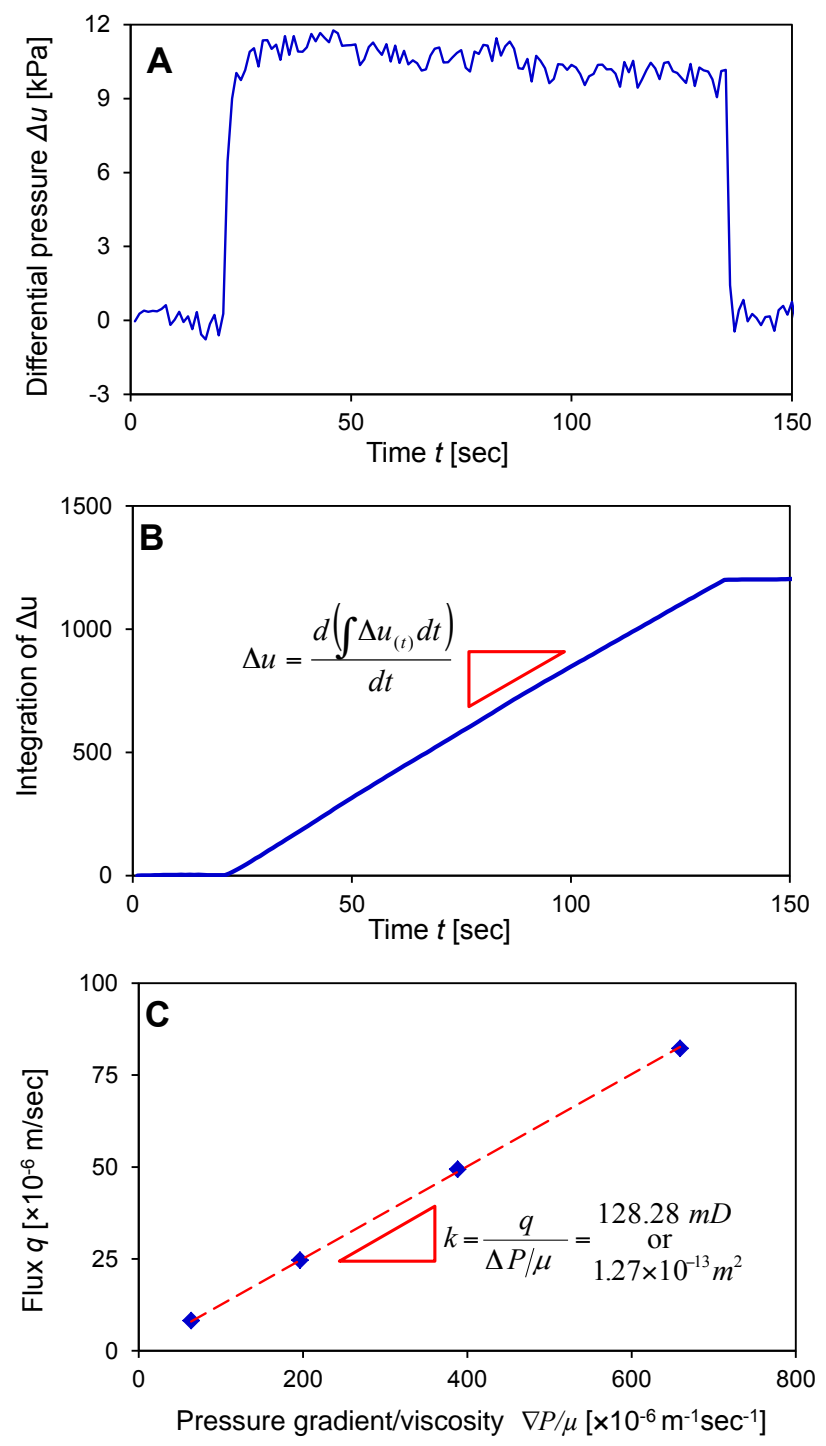

Figure 5. Water permeability measurement in the ESC for core $8 \mathrm{P}$ before dissociation. (A) Measured differential pressure versus time during pore fluid extraction under constant flux, with effective pressure $\sigma_{v}{ }^{\prime}=3 \mathrm{MPa}$, pore pressure $u=10 \mathrm{MPa}$. (B) The average differential pressure is determined using the slope of the integration of the measured differential pressure in $\mathbf{A}$ to cancel random noise. (C) Permeability is determined based on measurements under several different fluxes. The best fit of the $q$ versus $\nabla P / \mu$ slope gives the final permeability value. 

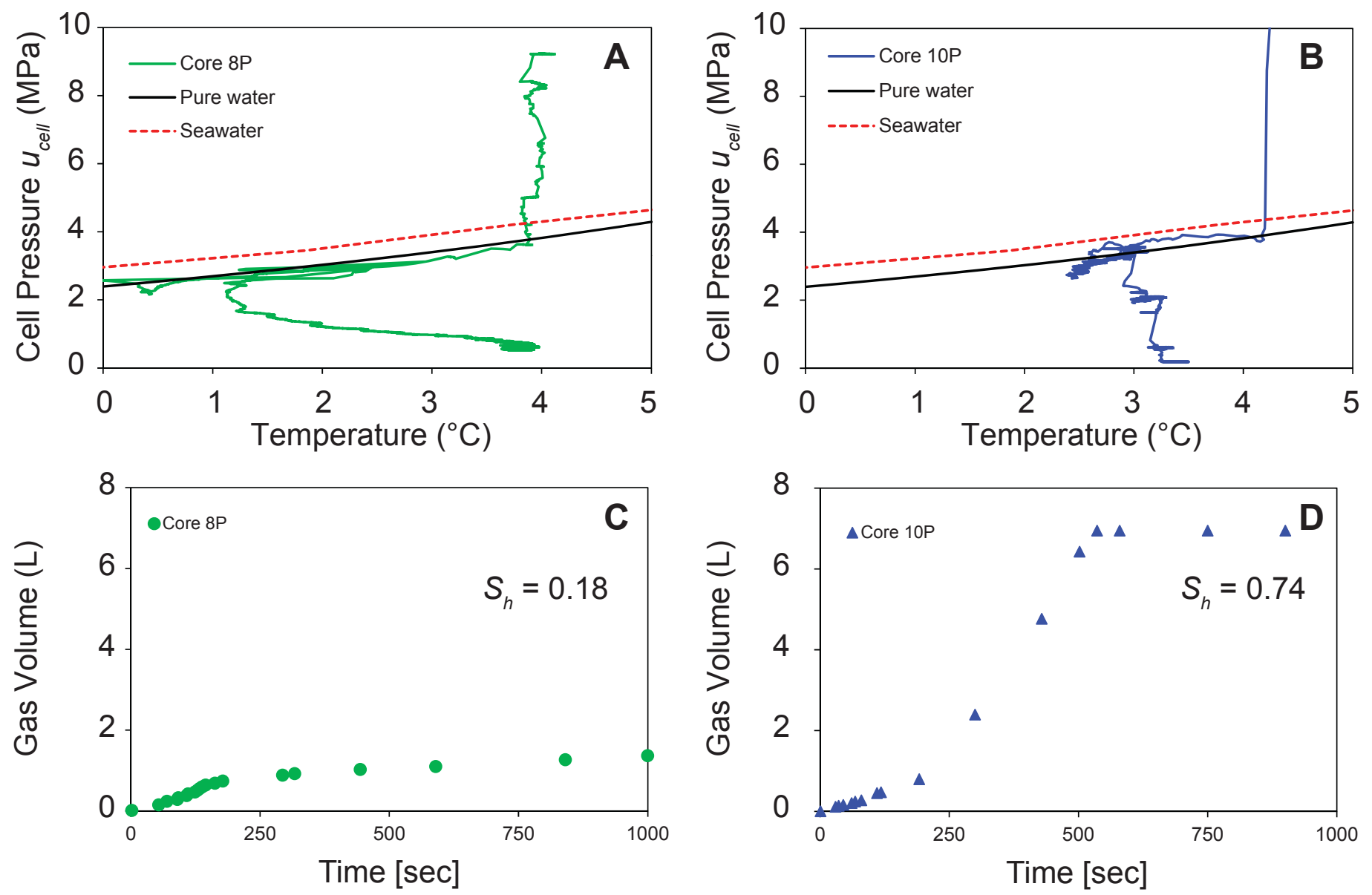

Figure 6. Gas production test at an effective stress of 3MPa in the ESC. Pressure and temperature changes during dissociation of core $8 \mathrm{P}(\mathbf{A})$ and $10 \mathrm{P}(\mathbf{B})$. The solid line is the phase boundary for methane hydrate in pure water and the dashed line is the phase boundary in seawater. Stability curves from Sloan and Koh (2007). Dissociation occurs along the freshwater stability curve, likely in response to dissociating hydrate being bathed in the freshwater generated as hydrate dissociates. Evolution along the freshwater stability curve is more noticeable in core 8P, which is depressurized from its base so dissociating fluids flow over the ESC thermocouple. Core 10P is depressurized at the specimen top, so dissociating fluids flow away from the thermocouple, reducing the measurement sensitivity to temperature changes. Gas volume collected during the dissociation for core $8 \mathrm{P}(\mathbf{C})$ and 10P $(\mathbf{D})$. Dissociation occurs too rapidly to establish thermal or chemical equilibrium with the surrounding material or pore water, leading to temperatures depressed close to $0^{\circ} \mathrm{C}$ and fresh water concentrations large enough to control dissociation conditions. 

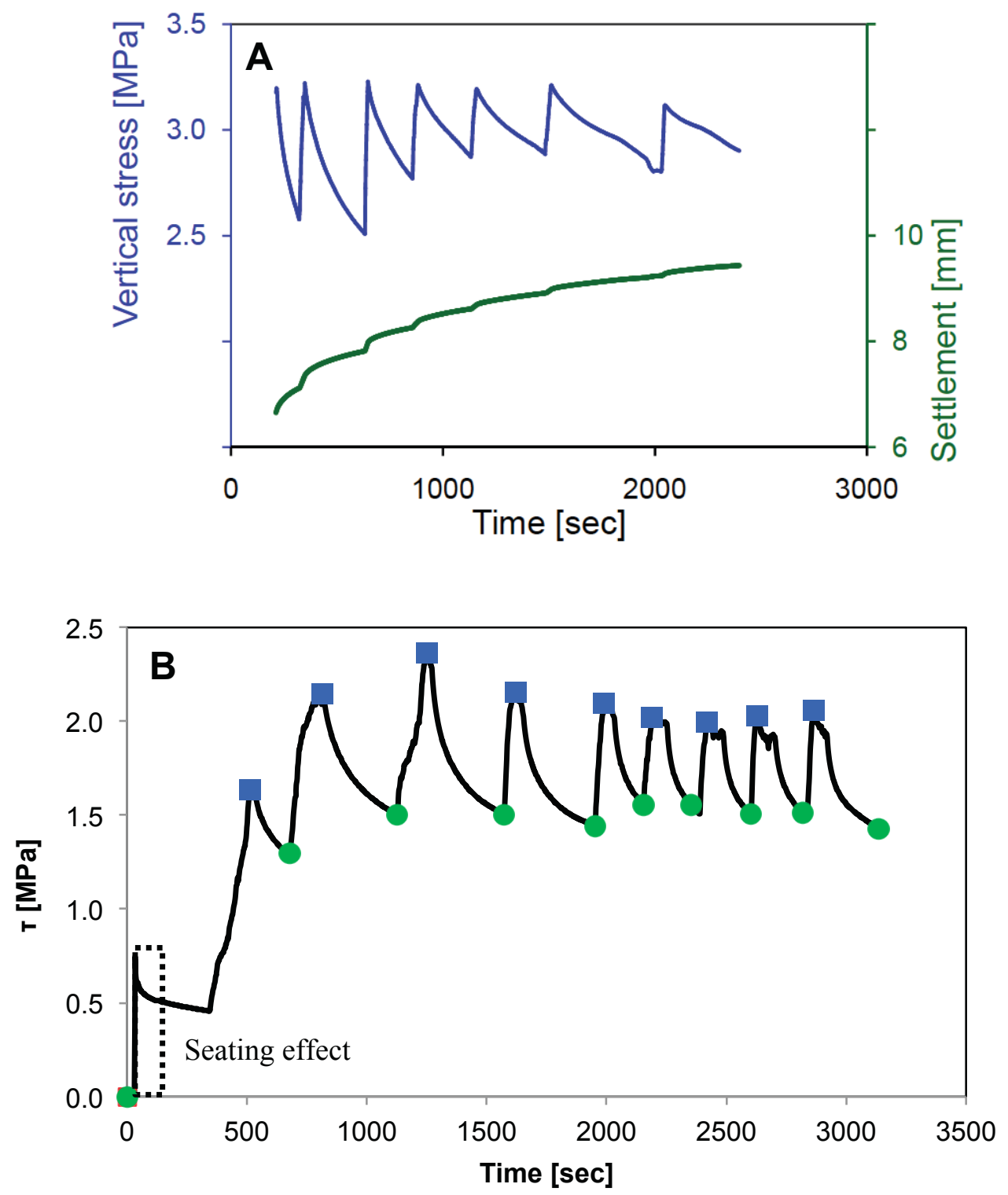

Figure 7. Typical results from the DSC. (A) Relaxation test after first loading; (B) shear test: blue dots show peak shear before relaxation, green dots show shear strength after shear relaxation. Dotted box indicates the initial "seating effect" as the specimen responds to the axial load contacting the non-parallel top and bottom faces of the specimen. 

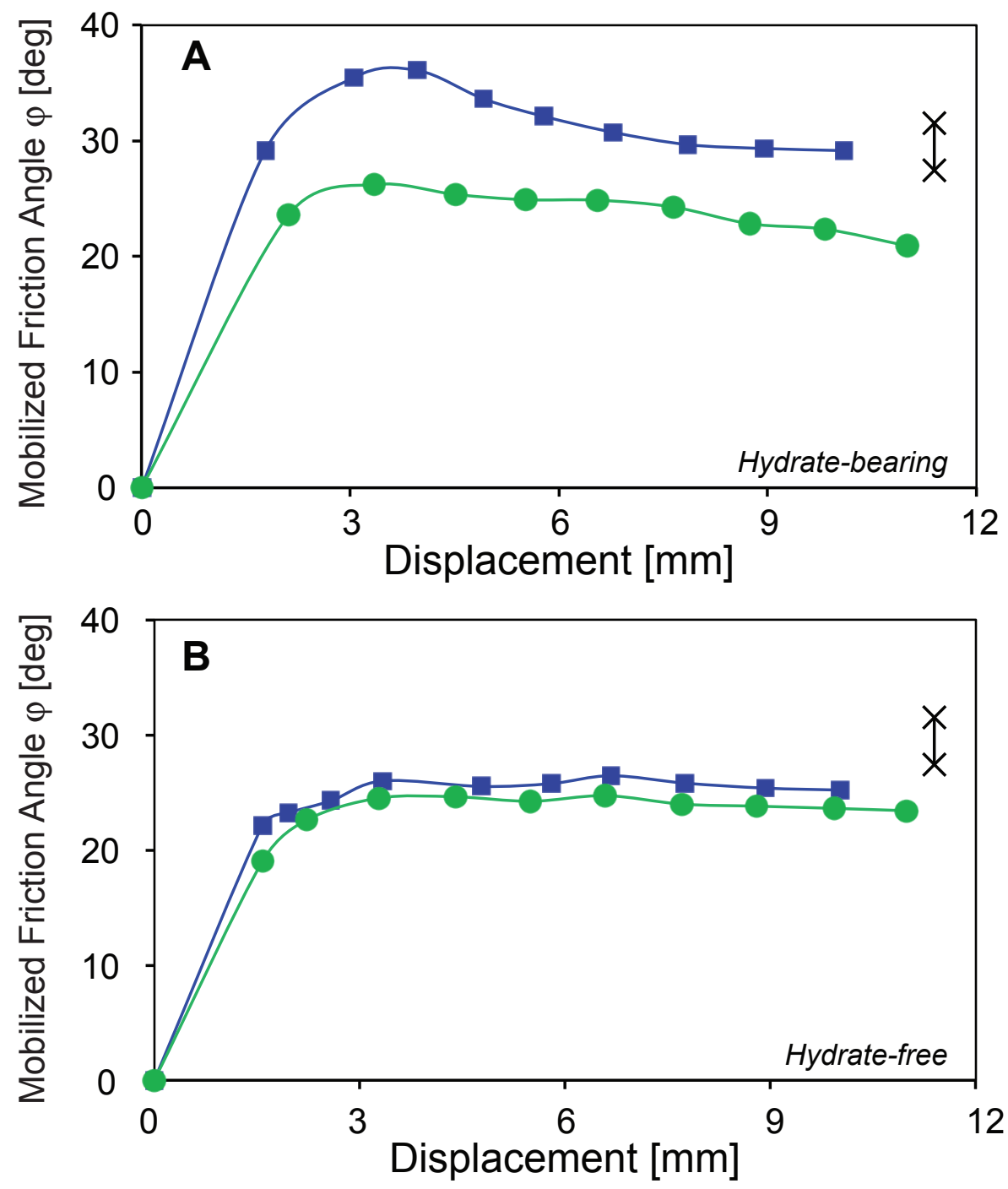

Figure 8. Mobilized friction angle, $\varphi$, measured in the DSC before (A) and after (B) hydrate dissociation in Core 20P. Blue squares and green circles, respectively, represent measurements made before and after the specimen relaxes after each displacement (see Fig. 7B). Hydrate significantly alters the friction angle when measured immediately after a displacement (blue squares), but values measured after the system relaxes (green circles) are controlled primarily by mineralogy. The specimen contains 12-15 wt\% smectite (Egawa et al., this volume). For reference, crosses are plotted for measurements on dry mixtures of quartz sand and $20 \mathrm{wt} \%$ smectite (Mollins et al., 1999). 


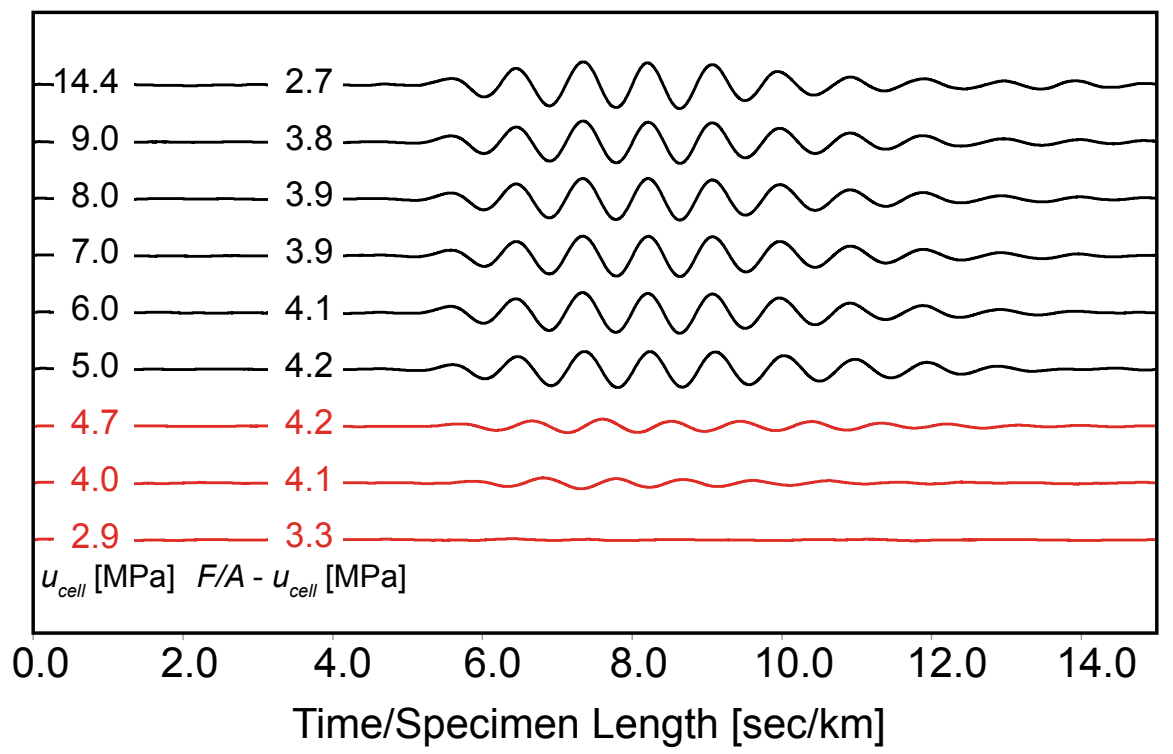

Figure 9. P-waveforms measured in the DSC for Core 10 while depressurizing the cell to cause dissociation. Depressurization progresses from top to bottom in the figure. Waveforms are normalized by their specimen lengths to cancel the effects caused by specimen shortening during dissociation. Black curves are measured while the specimen is within the hydrate stability conditions, red curves are measured after $u_{c e l l}$ is reduced below the hydrate stability pressure at $6^{\circ} \mathrm{C}$. Amplitude loss for pressures below the hydrate stability pressure (red curves) is in agreement with empirical results for the addition of gas to an otherwise water-saturated porous material (Murphy, 1982; Santamarina et al., 2001). 

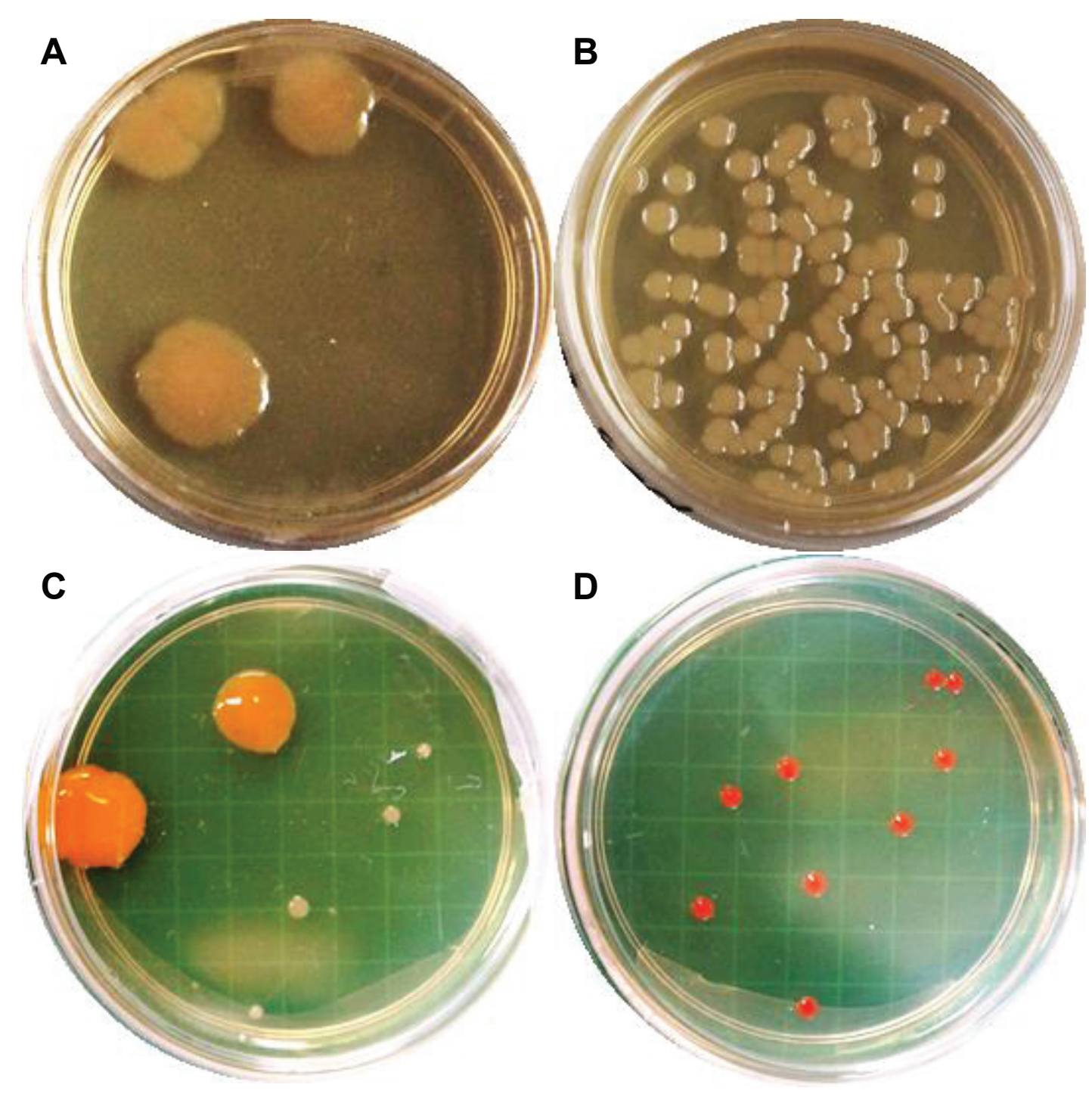

Figure 10. Sampling of the biological diversity in core $8 \mathrm{P}$ using the BIO chamber. Images are taken after culturing for 32 days at atmospheric pressure, under oxic conditions. Top row cultured at $4^{\circ} \mathrm{C}$, bottom row cultured at $30^{\circ} \mathrm{C}$. Depressurization rates and dilutions vary: (A) $7 \mathrm{MPa} / 2 \mathrm{sec}, 10^{-3}$ dilution; (B) $7 \mathrm{MPa} / 2 \mathrm{sec}, 10^{-1}$ dilution; (C) $7 \mathrm{MPa} / 1 \mathrm{~min}, 10^{-3}$ dilution; (D) $7 \mathrm{MPa} / 30 \mathrm{~min}, 10^{-1}$ dilution. Variety in colony color and edge morphology likely indicate the presence of several microbial species. Microbial identification is not part of the BIO chamber's specimen acquisition "proof-of-concept" test. 

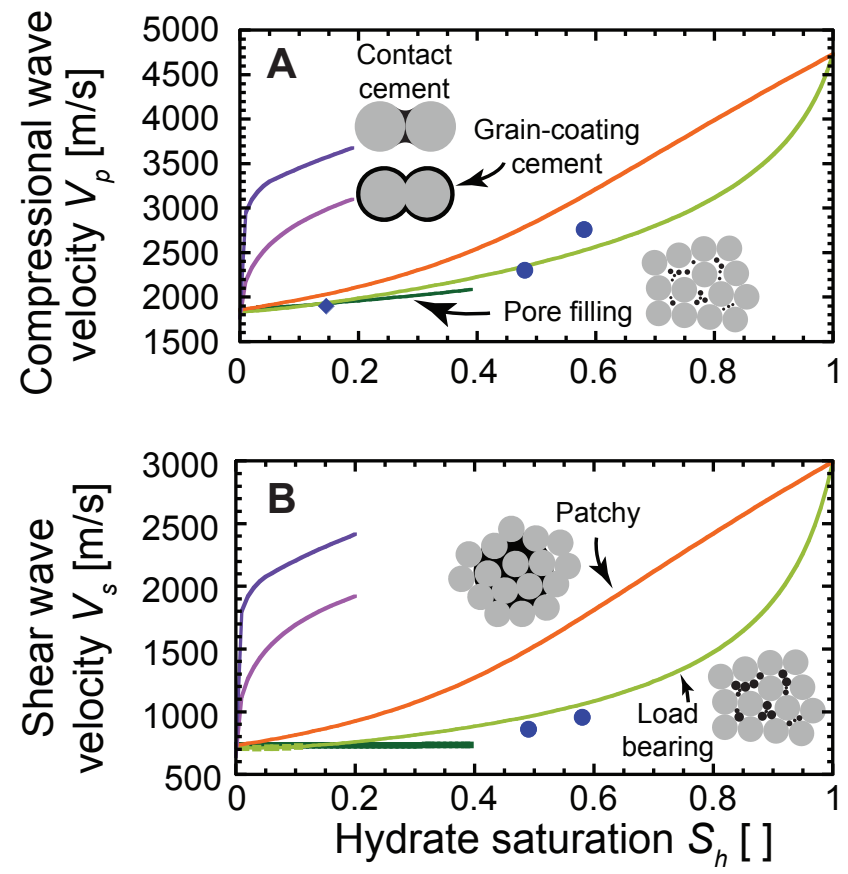

Figure 11. (A) Compressional $V_{P}$ and (B) Shear $V_{S}$ wave velocity in hydrate-bearing sands. Under gas-limited conditions in marine sands, hydrate nucleates and initially grows into the pore space (i.e. "pore filling"), to eventually become "loadbearing" as the hydrate volume in the pore increases (Yun et al., 2005). IPTC measurements in a high $S_{h}$ section of core $8 \mathrm{P}$ (filled circles), and DSC measurement in a low $S_{h}$ section of core 10P (filled diamond in $\mathbf{A}$ ) can all be fitted by the model that assumes hydrate is homogeneously distributed as a load-bearing component of the sediment (Dvorkin et al. 2000). Schematics show grey, circular sand grains and black hydrate mass. Cementation curves are also calculated from Dvorkin et al. (2000), and curves for sand with spherical hydrate patches are calculated from Berryman (1995). Theoretical curve color scheme is the same in $\mathbf{A}$ and $\mathbf{B}$. 


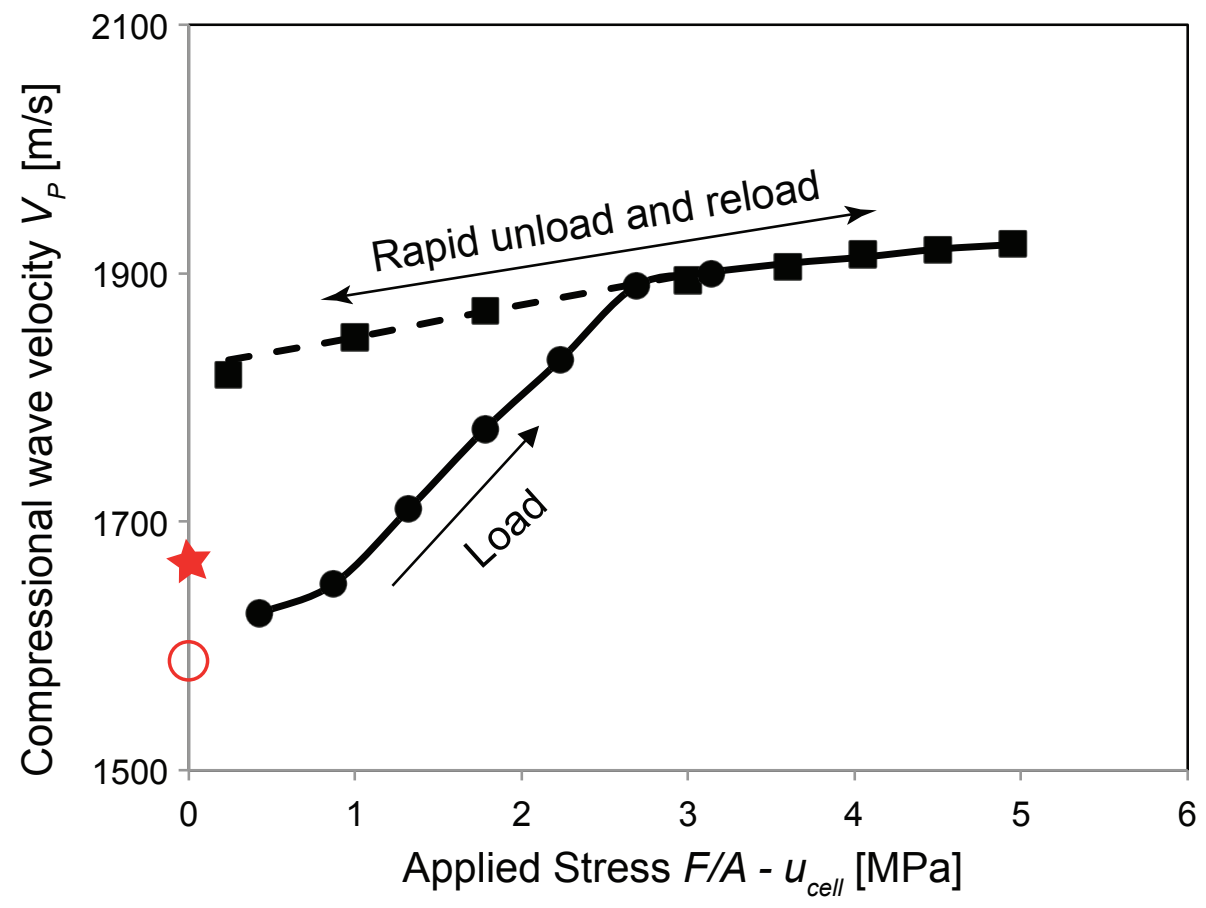

Figure 12. Dependence of compressional wave velocity $V_{P}$ on effective stress in the DSC specimen from core 10P. Pressure cores are collected and stored with no effective stress. The PCATS measurement of $V_{P}$ (red star, Suzuki et al., this volume) one week after collecting core 10P shows evidence of $V_{P}$ reduction from in situ values that is more significant that the reduction expected from rapid removal of the effective stress (filled black squares, measured in DSC). The core expansion, or aging observed by Nagano et al. (this volume), is likely responsible for the remaining drop in $V_{P}$ apparent in the PCATS measurement. Additional expansion and unloading at sediment grain contacts occurs during the subsequent 27 weeks of storage at zero effective stress, but within the hydrate stability conditions, causing an additional 5\% drop in $V_{P}$ (IPTC measurement, co-located with PCATS measurement, red circle). DSC reapplication of a vertical effective stress to the specimen reverses the unloading and aging effects on $V_{P}$ (filled black circles). The break in slope near $2.8 \mathrm{MPa}$ applied stress coincides with the in situ vertical effective stress, estimated to be $2.32 \mathrm{MPa}$. 


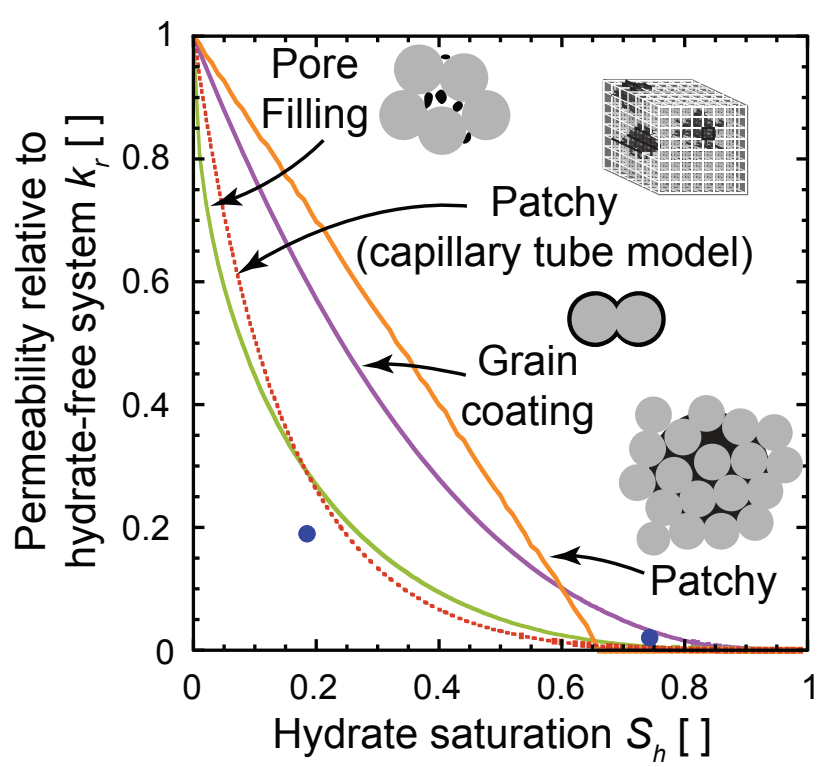

Figure 13. Measured permeability in hydratebearing sediment relative to the permeability in hydrate-free sediment (filled circle at $S_{h}=0.18$ for core $8 \mathrm{P}$, and 0.74 for core $10 \mathrm{P}$ ). Theoretical trends are shown for several possible hydrate morphologies (schematics have sediment shown in grey, hydrate in black). Results suggest hydrate is primarily forming as a non-cementing pore-fill (model in Kleinberg et al., 2003), as can be expected if hydrate initially forms in the largest pores through which pore fluid advection is strongest. If hydrate is assumed to be distributed in patches throughout the sediment, the relative permeability is overpredicted in the spherical-grain case (Berryman, 1995), but is in agreement with a modified Kozeny-Carman approach in which the pore space is assumed to be a network of water-filled capillaries (white segments) with hydrate forming a patchy filling of the largerdiameter capillaries (black segments, model in Dai and Seol, 2014). 


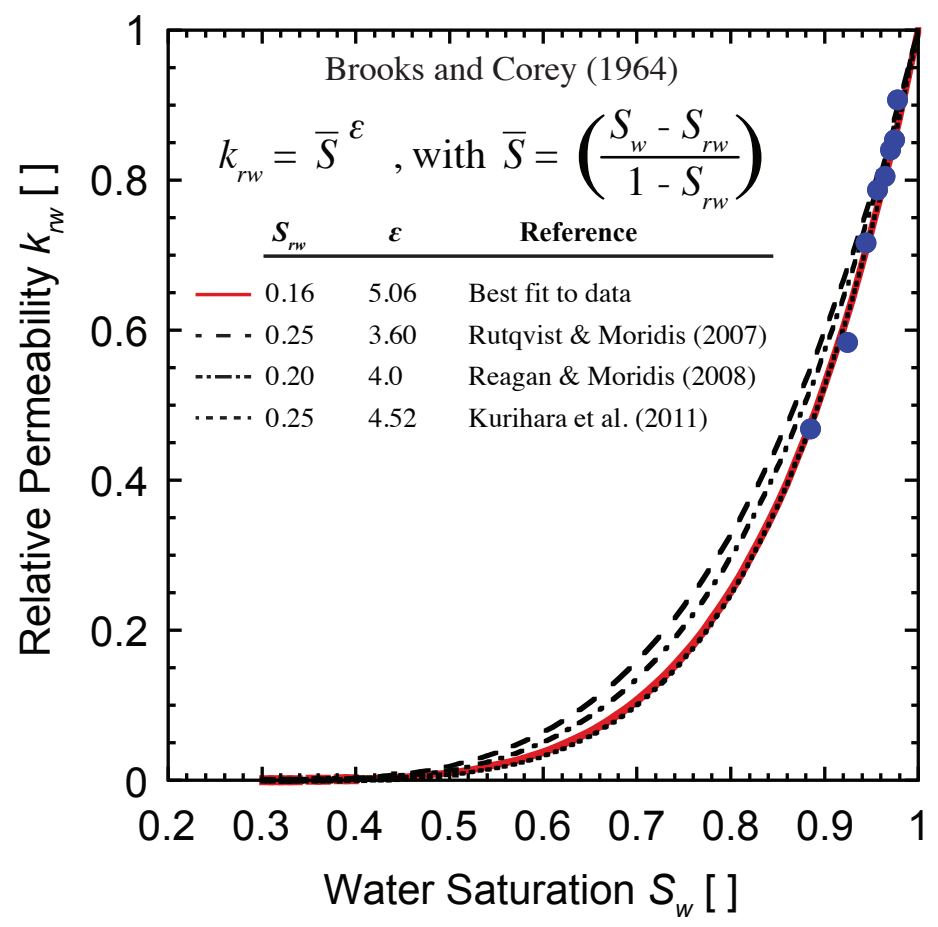

Figure 14. Permeability measurements for core $8 \mathrm{P}$ in the ESC after hydrate dissociation (blue circles), while the specimen pore space contains gas and the water saturation $S_{w}<1$. Permeability measurements are made at different pore pressure levels as the specimen is repressurized with water to $u_{\text {cell }}=10 \mathrm{MPa}$ at $18^{\circ} \mathrm{C}$ to resaturate the specimen without reforming hydrate. The measured residual water saturation after depressurization for this specimen is $S_{r w}=0.16$. Relative permeability $k_{r w}$ dependence on $S_{w}$ during repressurization can be estimated (solid curve) with the Brooks and Corey (1964) model, where the best fit curve is nearly identical to the prediction using the parameters from Kurihara et al., (2011). 


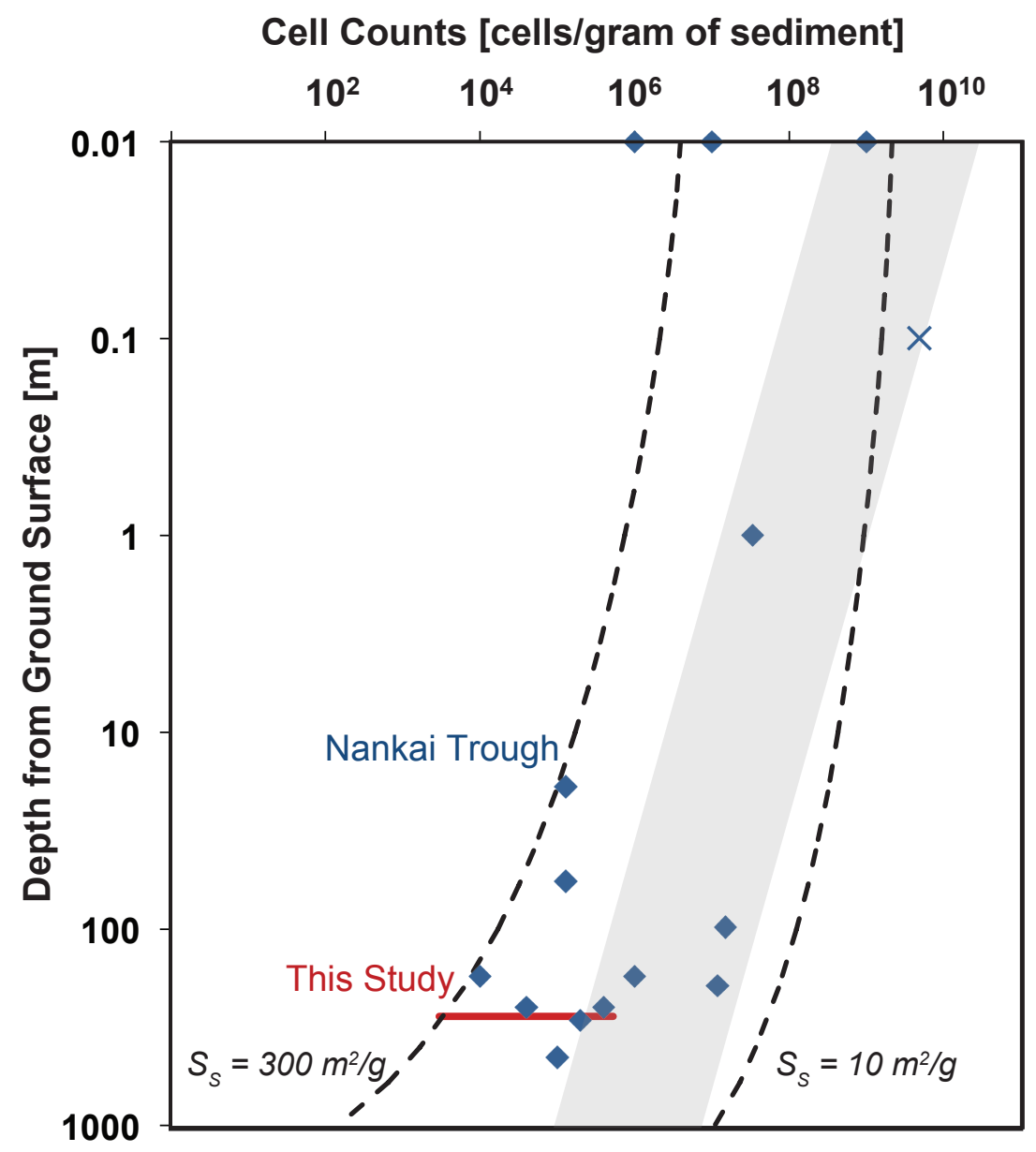

Figure 15. Dependence of cell count on depth from the ground surface. Cells can only occupy pores larger than the cell size; the probability of finding pores of viable host size decreases with depth due to compaction, and with grain specific surface $S_{S}$ due to the presence of fine particles in the pore space (Phadnis and Santamarina, 2011). Nankai Trough data from other studies are included (Reed et al., 2002; Li et al., 1999; Kormas et al., 2003; Mills et al., 2012; Newberry et al., 2004). The shaded region represents results from other locations compiled in Parkes et al. (1994, 2000). Cell counts in this study were taken from a BIO specimen with $S_{S}=19.4$ $\mathrm{m}^{2} / \mathrm{g}$, but the cell counts include only live, culturable aerobes, so a reduced cell count is expected relative to theoretical estimates (dashed curves) and compiled data (symbols and shaded region), which all include living and dead organisms. Compiled data points are obtained based either on cell weight (x), or a staining method (solid diamonds). 